\title{
Fine and ultrafine particles in the Zürich (Switzerland) area measured with a mobile laboratory: an assessment of the seasonal and regional variation throughout a year
}

\author{
N. Bukowiecki, J. Dommen, A. S. H. Prévôt, E. Weingartner, and U. Baltensperger \\ Laboratory of Atmospheric Chemistry, Paul Scherrer Institut, CH-5232 Villigen PSI, Switzerland \\ Received: 24 March 2003 - Published in Atmos. Chem. Phys. Discuss.: 23 May 2003 \\ Revised: 10 September 2003 - Accepted: 10 September 2003 - Published: 24 September 2003
}

\begin{abstract}
On occasion of the project YOGAM (year of gas phase and aerosol measurements), the spatial and temporal variation of selected aerosol and gas phase parameters was assessed for the Zürich (Switzerland) area with a new mobile pollutant measurement laboratory. This assessment based on on-road measurements along a specified route on selected days during different seasons in 2001/2002, covering urban, suburban and rural regions. Special focus was put on the investigation and characterization of particles in the fine (particle diameter $\mathrm{D}<2.5 \mu \mathrm{m})$ and ultrafine $(\mathrm{D}<100 \mathrm{~nm}$ ) size ranges. Analysis of Variance (ANOVA) showed that the variance of all considered fine and ultrafine aerosol parameters (i.e. particle background and total number concentration for particles larger than $3 \mathrm{~nm}$, number concentrations in the size ranges $7-30 \mathrm{~nm}$ and $80-140 \mathrm{~nm}$, as well as the active surface area concentration) was significantly larger for dayto-day than for spatial variation. However, Principal Component Analysis (PCA) found a similar regional pollution pattern within every single measuring day. Lowest particle background levels $(D>3 \mathrm{~nm})$ were found in rural areas at higher elevation $\left(15000 \mathrm{~cm}^{-3}\right)$, while corresponding mean background values for urban and freeway-influenced areas were typically $35000 \mathrm{~cm}^{-3}$ and $>80000 \mathrm{~cm}^{-3}$, respectively. Meteorology, i.e. prevailing weather conditions not only governed the day-to-day concentration variations in the selected area, but also influenced the formation of primary (directly traffic-related) and in few cases secondary (biogenic or anthropogenic) ultrafine particles. Overall, low temperatures regularly enhanced primary ultrafine particle formation in urban areas. There was a possible indication for relatively low number concentrations of secondary ultrafine particles during a few warm and sunny spring days. Mobile measurements as they were performed in this study have been shown to be suitable for pollutant assessments to obtain good infor-
\end{abstract}

Correspondence to: A. S. H. Prévôt

(andre.prevot@psi.ch) mation on spatial and day-to-day variability. For experimental studies concerning spatial resolution on a relatively short time scale ( $<1$ day), a mobile measurement design may even be more appropriate than a network of stationary measuring sites.

\section{Introduction}

In recent years the potential of particulate matter to cause adverse health effects has been investigated in numerous epidemiological and laboratory studies. For PM10 (mass concentration of particles with an aerodynamic diameter $D_{a}<10 \mu \mathrm{m}$ ) and PM2.5 (fine particles, $D_{a}<2.5 \mu \mathrm{m}$ ), a significant correlation with adverse health effects could be shown (Dockery et al., 1993; Katsouyanni et al., 1997; Laden et al., 2001; Pope et al., 1995; Schindler et al., 2001). For ultrafine particles (particle diameter $D<100 \mathrm{~nm}$ ) extensive epidemiological studies have not been performed yet, but the few available investigations point to an increased health effect potential of particles in this size range due to their special interaction pattern in the human airways (Donaldson et al., 1998; Oberdörster and Utell, 2002; U.S. Health Effects Institute, 2002; Wichmann and Peters, 2000). In ambient aerosol research, strong efforts have been made in the last years to obtain a clearer picture not only on the spatial and temporal distribution of PM10 and PM2.5, but also on other aerosol parameters like particle number size distributions, surface or volume. Ambient ultrafine particles have gained special attention in the last years and typically show complex formation and occurrence patterns. So far, it has been recognized that ambient ultrafines can be split into primary and secondary ultrafine particles (Baltensperger et al., 2002). Primary ultrafines and nanoparticles $(D<50 \mathrm{~nm})$ are mostly traffic-related and are rapidly formed by nucleation during the dilution and cooling of freshly emitted gaseous combustion exhaust in the atmosphere, depending 
on the meteorological conditions. It has been shown that their formation is favored at low ambient temperatures and is lower for low-sulfur fuel vehicles (Abdul-Khalek et al., 1999, 2000; Kittelson et al., 2002). When formed, they show large number concentrations in the area of emission, but have a limited lifetime $(<10 \mathrm{~min}$ in urban areas) and therefore a typical area of influence of $100 \mathrm{~m}-1 \mathrm{~km}$ (Capaldo and Pandis, 2001). They are composed of hydrocarbons and a minor fraction of sulphuric acid and water, and are believed to partially originate from lube oil substances in vehicle engines (Tobias et al., 2001). On the other hand, secondary ultrafines describe ambient ultrafine particles that are not directly formed immediately after emission, but are rather formed from chemically transformed gaseous precursors, i.e. by condensation of products from atmospheric reactions (e.g. photochemical reactions, see Mäkelä et al., 2000). Nucleation bursts of secondary ultrafines have been reported to occur worldwide in remote, rural and even urban areas and are strongly influenced by meteorological parameters like solar radiation or temperature, but also by background concentrations of other pollutants, i.e. the local particle background concentration (Baltensperger et al., 2002; Birmili and Wiedensohler, 2000; Boy and Kulmala, 2002a,b; McMurry and Woo, 2002). Their lifetime and composition is so far less elucidated, though there is evidence that they mainly consist of organics and that they persist longer (in the range of hours) in the atmosphere than primary ultrafines, mainly due to slower coagulation with typically lower concentration levels of background aerosol (O'Dowd et al., 2002). However, for numerous regions no area-covering inventory of combined aerosol and other parameters exists for a longer period of time. Such monitoring is often restricted to PM10 or PM2.5 due to national regulation standards.

In an earlier publication (Bukowiecki et al., 2002) we showed a case study involving mobile pollutant measurements in the Zürich (Switzerland) area, in which we investigated spatial and temporal differences in pollutant levels for an autumn two-day period. While we focused on short-time signal variations and day/night differences in that case study, this paper will present an analysis of particulate pollution variation on a larger time scale. It is the goal of this study to obtain statistical information on both spatial dependence and seasonality of particulate air pollution in the Zürich area with the help of mobile pollutant measurements, and also to have a closer look at the processes leading to the formation of fine and ultrafine particles. A focus will be put on particle number size distributions, total particle number concentration, active surface area and carbon monoxide measurements. Despite of the limited numbers of parameters we had available from stationary measuring sites, we attempted to evaluate whether the use of a mobile laboratory is a promising approach to measure and study processes that normally are monitored by a network of stationary monitoring sites.

\section{Methods}

\subsection{Experimental}

On occasion of the research project YOGAM (Year of Gas Phase and Aerosol Measurements, 2001/2002), a mobile laboratory was constructed at the Paul Scherrer Institute (Villigen, Switzerland), allowing for on-road measurements of a variety of aerosol parameters and gas phase parameters, along with geographical information (GPS, Garmin IIplus) and meteorological data (temperature, pressure, humidity, global radiation and relative wind direction). The setup of the mobile laboratory is discussed in detail in Bukowiecki et al. (2002). Data included in this paper were measured by a scanning mobility particle sizer (SMPS, DMA TSI 3071 and CPC TSI 3010), a condensation particle counter (CPC, TSI UCPC 3025), an optical particle counter (OPC, Grimm 1.108), a diffusion charging sensor (DC, Matter Engineering LQ1-DC) and a carbon monoxide (CO) monitor (Aerolaser AL-5002). Since measurements could be performed while driving, highly time-resolved ( $1 \mathrm{~s}-3 \mathrm{~min}$ time resolution for most parameters) and spatially resolved information (continuously) on the ground pollutant level in the testing area was obtained. During YOGAM, a selected route in the Zürich area (Fig. 1) was driven on a regular base throughout the course of a year, including downtown Zürich ( $400 \mathrm{~m}$ a.s.l.), suburban areas (400-500 $\mathrm{m}$ a.s.1.) as well as rural sites (500$900 \mathrm{~m}$ a.s.l.). For the time frame chosen, additional data from official monitoring stations were available for comparison.

\subsection{Data analysis strategy}

The large number of parameters measured during YOGAM required a careful development of a suitable data analysis strategy. In contrast to stationary measurements, mobile measurements have a simultaneous signal variation in time and space. To find a way to categorize such data it is necessary to know the signal dynamics along both the time and location axis. As shown earlier (Bukowiecki et al., 2002), regional signal variations $(<5 \mathrm{~min})$ of the measured parameters occurred more rapidly than temporal variation $(<4 \mathrm{~h})$. Thus, a temporal classification of the data in morning and afternoon loops on the YOGAM route was appropriate. As shown in the next section, spatial classification of the data was achieved by binning the raw data into different location bins along our measuring route. This binning per location and measuring day allowed for analysis of variance (ANOVA), which turned out to be especially suitable for looking at the whole-year data set with respect to signal variations at different locations and different days. However, this 3-dimensional measuring approach (signal vs. time and twodimensional space) and the large number of parameters measured push the use of low-dimensional statistics to a limit. Hidden connections can essentially influence and jeopardize the pure investigation of single dependencies. Multivariate 

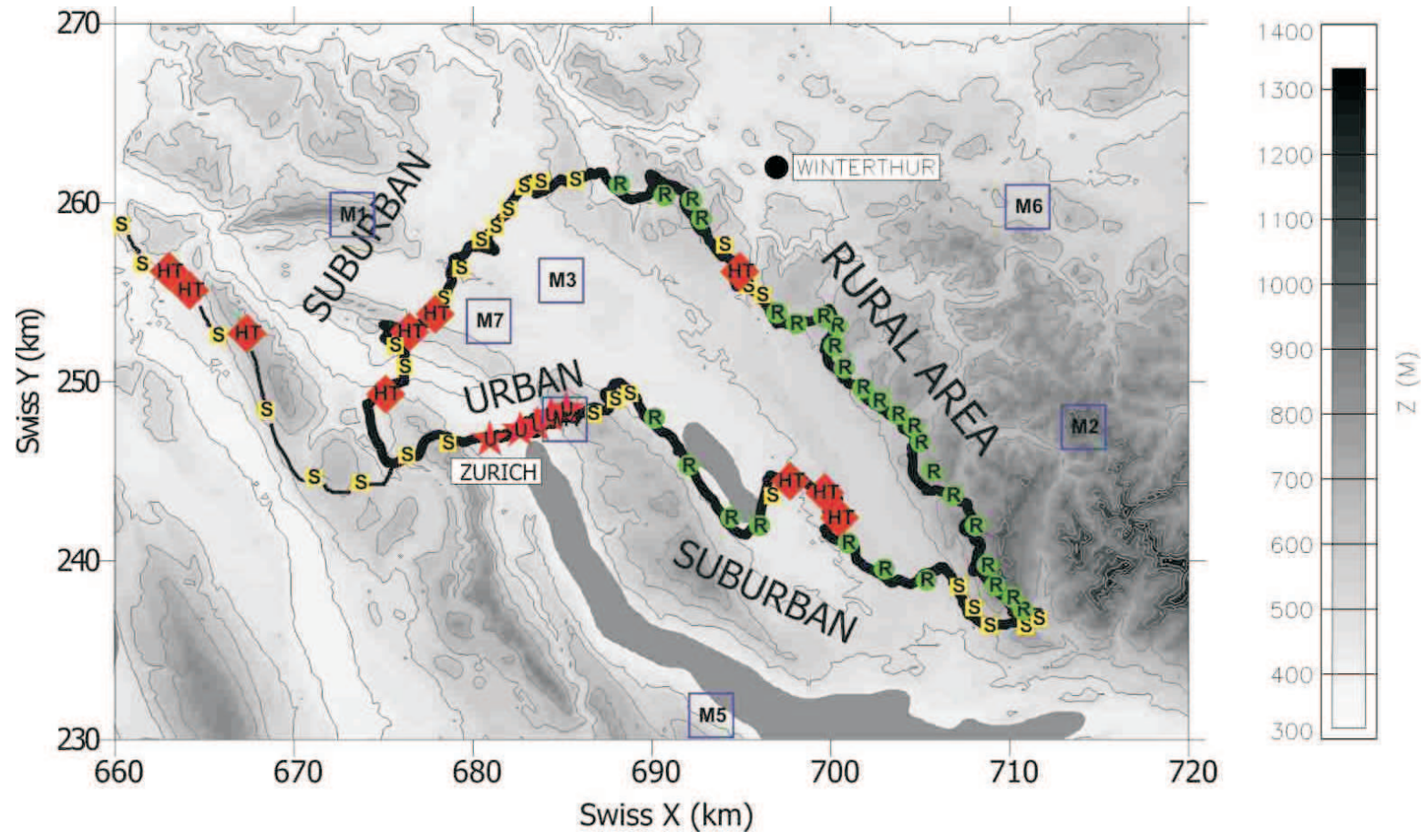

Fig. 1. Main (solid black line) and access (thin black line) route of the YOGAM project. Dark gray filled areas represent lakes, and the contours show the altitude profile ( $\mathrm{z}$, meters above sea level). The two main cities in the selected area, Zürich and Winterthur, are also indicated. Swiss X and Y designate the coordinates in the official Swiss kilometer grid. Additionally, location bin classifications according to Table 1 (R: rural, S: suburban, U: urban, HT: heavy-traffic areas) and official meteorological monitoring stations (M1-M7) are shown.

statistical tools are often used in ambient aerosol research. Principal Component Analysis (PCA) and Factor Analysis (FA) are useful statistical methods to explore and explain relevant variations in large data sets. In source apportionment studies these techniques are often used for quantitative analysis and underlie a large number of critical boundary conditions. For the YOGAM data set, a PCA was selected as an adequately simple multivariate tool to find unobvious patterns in the data and reveal hidden correlations between different parameters. The findings of PCA were then used as input for further process studies.

\subsection{Data preparation}

This section describes how raw data collected during YOGAM were processed to finally get appropriate input data for ANOVA and PCA. With the help of GPS, every raw data point ( $1 \mathrm{~s}$ intervals) of the total aerosol number and surface area concentration as well as of the CO concentration measurements was assigned to a geographical position. In a first step, we defined a set of location bins along the YOGAM route, based on geography and population density considerations. Thus, all raw data points were attributed to corresponding location bins. In this way, 75 location bins were obtained (see Table 1 and Fig. 1), each containing ap- proximately $180-360$ raw data points, which corresponded to 3-6 min driving along the route with the mobile laboratory (except the Zürich city bins, which also included midday stationary measurements during 30-60 min). Since local changes in location type occurred very quickly while driving along the YOGAM route (often within a few minutes, which is faster than the average day-to-day deviation from the route schedule $( \pm 1.5 \mathrm{~h})$ ), the concept of forming location bins was found to be more reliable than a time-averaging approach. All parameters were corrected for instrument and sampling time delays (see Bukowiecki et al., 2002), and all data were checked for plausibility and validity. Next, the data in each location bin were statistically treated according to Table 2 . For the CPC, both average concentrations and 5\% percentile values were formed. The latter statistical parameter has been shown to be suitable to eliminate plumes originating from single vehicles and thus to estimate the local (i.e. the roadnear) particle background (which is influenced both by fresh traffic plumes and aged/dispersed plumes of anthropogenic and biogenic origin, see Bukowiecki et al., 2002). For all meteorological parameters and carbon monoxide, average values per location bin were calculated, except for the global radiation. Since numerous low values resulting from bridges, buildings, trees or tunnels biased the measured global radiation throughout a measuring day, the use of $95 \%$ percentiles 
Table 1. Classification of individual stretches of the YOGAM route into 75 location bins regarding altitude and vicinity to anthropogenic activity. R: Rural, S: Suburban: U: Urban (downtown Zürich), HT: Heavy traffic area. Altitudes are indicated in meters above sea level. The bins are sorted chronologically, in the order how they were passed while driving on the route. A normal measuring day included the access route from Paul Scherrer Institute to the loop starting point (1-9), followed by two subsequent runs along bins 10-75

\begin{tabular}{|c|c|c|c|c|c|c|c|c|c|c|c|c|c|c|c|}
\hline Bin No. & 1 & 2 & 3 & 4 & 5 & 6 & 7 & 8 & 9 & 10 & 11 & 12 & 13 & 14 & 15 \\
\hline Altitude & 356 & 364 & 398 & 432 & 446 & 497 & 576 & 577 & 564 & 515 & 527 & 428 & 424 & 433 & 482 \\
\hline Type & $\mathbf{R}$ & $\mathbf{S}$ & $\mathbf{S}$ & HT & HT & $\mathbf{S}$ & $\mathbf{S}$ & $\mathbf{S}$ & $\mathbf{S}$ & $\mathbf{S}$ & $\mathbf{S}$ & $\mathbf{U}$ & $\mathbf{U}$ & $\mathbf{U}$ & $\mathbf{U}$ \\
\hline Bin No. & 16 & 17 & 18 & 19 & 20 & 21 & 22 & 23 & 24 & 25 & 26 & 27 & 28 & 29 & 30 \\
\hline Altitude & 539 & 579 & 485 & 446 & 459 & 463 & 464 & 449 & 469 & 485 & 503 & 534 & 529 & 542 & 540 \\
\hline Type & $\mathbf{U}$ & $\mathbf{S}$ & $\mathbf{S}$ & $\mathbf{S}$ & $\mathbf{R}$ & $\mathbf{R}$ & $\mathbf{R}$ & $\mathbf{R}$ & $\mathbf{S}$ & HT & HT & HT & $\mathbf{R}$ & $\mathbf{R}$ & $\mathbf{R}$ \\
\hline Bin No. & 31 & 32 & 33 & 34 & 35 & 36 & 37 & 38 & 39 & 40 & 41 & 42 & 43 & 44 & 45 \\
\hline Altitude & 593 & 588 & 550 & 570 & 638 & 776 & 887 & 830 & 768 & 793 & 732 & 696 & 665 & 666 & 696 \\
\hline Type & $\mathbf{S}$ & $\mathbf{S}$ & $\mathbf{S}$ & $\mathbf{S}$ & $\mathbf{S}$ & $\mathbf{R}$ & $\mathbf{R}$ & $\mathbf{R}$ & $\mathbf{R}$ & $\mathbf{R}$ & $\mathbf{R}$ & $\mathbf{R}$ & $\mathbf{R}$ & $\mathbf{R}$ & $\mathbf{R}$ \\
\hline Bin No. & 46 & 47 & 48 & 49 & 50 & 51 & 52 & 53 & 54 & 55 & 56 & 57 & 58 & 59 & 60 \\
\hline Altitude & 694 & 643 & 633 & 626 & 615 & 602 & 615 & 590 & 544 & 525 & 555 & 598 & 632 & 642 & 590 \\
\hline Type & $\mathbf{R}$ & $\mathbf{R}$ & $\mathbf{R}$ & $\mathbf{R}$ & $\mathbf{R}$ & $\mathbf{R}$ & $\mathbf{R}$ & $\mathbf{R}$ & $\mathbf{S}$ & $\mathbf{S}$ & HT & $\mathbf{S}$ & $\mathbf{R}$ & $\mathbf{R}$ & $\mathbf{R}$ \\
\hline Bin No. & 61 & 62 & 63 & 64 & 65 & 66 & 67 & 68 & 69 & 70 & 71 & 72 & 73 & 74 & 75 \\
\hline Altitude & 468 & 543 & 467 & 428 & 428 & 446 & 453 & 485 & 465 & 458 & 503 & 438 & 418 & 420 & 467 \\
\hline Type & $\mathbf{R}$ & $\mathbf{S}$ & $\mathbf{S}$ & $\mathbf{S}$ & $\mathbf{S}$ & $\mathbf{S}$ & $\mathbf{S}$ & $\mathbf{S}$ & $\mathbf{S}$ & HT & HT & $\mathbf{S}$ & $\mathbf{S}$ & HT & HT \\
\hline
\end{tabular}

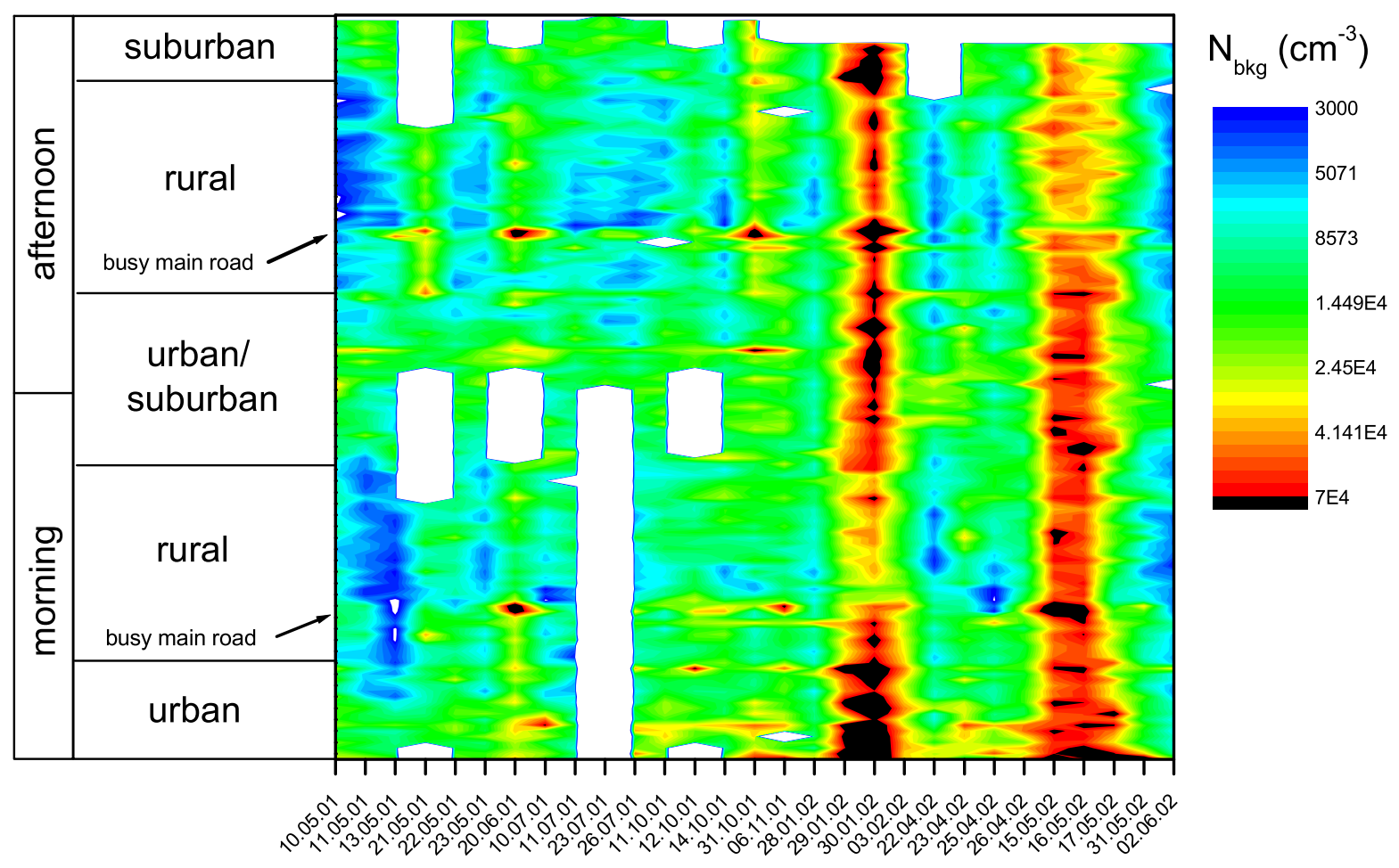

Fig. 2. Seasonal and spatial particle background variation for the Zürich (Switzerland) area. A contour plot of the particle background number concentration $(\mathrm{D}>3 \mathrm{~nm})$ is shown, calculated with the $5 \%$ percentile of the CPC total particle number concentration (see Bukowiecki et al., 2002b). The x-axis represents the days selected for YOGAM measurements (including spring and summer 2001), while the y-axis depicts a morning and afternoon loop along the YOGAM route (in chronological order).

was shown to be appropriate to get the regional daily variation of this parameter. Average values were also calculated for the active surface area, since the measured DC signal in- cluded too much noise for reasonable percentile calculations. For all parameters, standard deviations were calculated for every location bin. Furthermore, SMPS and OPC particle 
Table 2. Parameters measured during YOGAM used for the assessment presented in this paper. For every parameter it is indicated (a) how raw data was treated to obtain the location bin values, (b) how individual parameters are connected to other parameters and (c) how they eventually were transformed in this study to become normally distributed (sqrt=square root). N: Number concentration, S: Surface area concentration, V: Volume concentration. Numbers in brackets indicate size ranges (in $\mathrm{nm}$ ). $\mathrm{N}_{\text {tot }}$ and $\mathrm{N}_{\text {bkg }}$ values were derived from condensation particle counter measurements (CPC TSI CPC 3025, D $>3 \mathrm{~nm}$ ), while the rest of the N, S and V based parameters were obtained from SMPS (scanning mobility particle sizer) and OPC (optical particle counter) measurements, see text and Bukowiecki et al. (2002b)

\begin{tabular}{|c|c|c|c|c|}
\hline Parameter & $\begin{array}{c}\text { Raw data } \\
\text { time resolution }\end{array}$ & Treatment & Dependencies & Transformation \\
\hline $\mathrm{N}(<30)$ & $3 \min$ & average & - & $\log _{10}$ \\
\hline $\mathrm{N}(30-80)$ & $3 \mathrm{~min}$ & average & - & $\log _{10}$ \\
\hline $\mathrm{N}(80-140)$ & $3 \mathrm{~min}$ & average & - & $\log _{10}$ \\
\hline $\mathrm{N}(140-310)$ & $3 \mathrm{~min}$ & average & - & $\log _{10}$ \\
\hline $\mathrm{N}_{\text {tot }}(\mathrm{OPC})$ & $6 \mathrm{~s}$ & average & - & sqrt \\
\hline $\mathrm{N}_{\text {tot }}=\mathrm{CPC}($ mean $)$ & $1 \mathrm{~s}$ & average & - & $\log _{10}$ \\
\hline $\mathrm{N}_{\mathrm{bkg}}=\mathrm{CPC}($ background $)$ & $1 \mathrm{~s}$ & $5 \%$ percentile & - & $\log _{10}$ \\
\hline $\mathrm{S}(<30)$ & $3 \min$ & average & $\sim \mathrm{ND}^{2}$ & $\log _{10}$ \\
\hline $\mathrm{S}(30-80)$ & $3 \mathrm{~min}$ & average & $\sim \mathrm{ND}^{2}$ & $\log _{10}$ \\
\hline $\mathrm{S}(80-140)$ & $3 \mathrm{~min}$ & average & $\sim \mathrm{ND}^{2}$ & $\log _{10}$ \\
\hline$S(140-310)$ & $3 \min$ & average & $\sim \mathrm{ND}^{2}$ & $\log _{10}$ \\
\hline $\mathrm{S}_{\mathrm{tot}}(\mathrm{OPC})$ & $6 \mathrm{~s}$ & average & $\sim \mathrm{ND}^{2}$ & sqrt \\
\hline $\mathrm{V}(<30)$ & $3 \mathrm{~min}$ & average & $\sim \mathrm{ND}^{3}$ & $\log _{10}$ \\
\hline $\mathrm{V}(30-80)$ & $3 \mathrm{~min}$ & average & $\sim \mathrm{ND}^{3}$ & $\log _{10}$ \\
\hline$V(80-140)$ & $3 \min$ & average & $\sim \mathrm{ND}^{3}$ & $\log _{10}$ \\
\hline $\mathrm{V}(140-310)$ & $3 \mathrm{~min}$ & average & $\sim \mathrm{ND}^{3}$ & $\log _{10}$ \\
\hline $\mathrm{V} 1=\mathrm{V}(<1000)$ & $3 \mathrm{~min}$ & average & $\sim \mathrm{ND}^{3}$ & sqrt \\
\hline $\mathrm{V} 2.5=\mathrm{V}(<2500)$ & $3 \mathrm{~min}$ & average & $\sim \mathrm{ND}^{3}$ & sqrt \\
\hline $\mathrm{V} 10=\mathrm{V}(<10000)$ & $3 \mathrm{~min}$ & average & $\sim \mathrm{ND}^{3}$ & sqrt \\
\hline $\mathrm{V}_{\text {tot }}(\mathrm{OPC})$ & $6 s$ & average & $\sim \mathrm{ND}^{3}$ & sqrt \\
\hline $\mathrm{DC}$ & $1 \mathrm{~s}$ & average & - & sqrt \\
\hline $\mathrm{CO}$ & $1 \mathrm{~s}$ & average & - & $\log _{10}$ \\
\hline Altitude (Alt) & $1 \mathrm{~s}$ & average & - & $\log _{10}$ \\
\hline Pressure (Press) & $1 \mathrm{~s}$ & average & $\sim$ Alt $^{-1}$ & $\log _{10}$ \\
\hline Temperature (temp) & $1 \mathrm{~s}$ & average & - & - \\
\hline Relative Humidity (RH) & $1 \mathrm{~s}$ & average & - & $\log _{10}$ \\
\hline Global Radiation (GR) & $1 \mathrm{~s}$ & $95 \%$ percentile & - & - \\
\hline
\end{tabular}

size distributions were linked, to obtain an average size distribution from $7 \mathrm{~nm}$ to 10 micrometer for every location bin. Based on the focus of interest of this study, we calculated several comprehensive integrated sum parameters for different size ranges from the size distribution data (see Table 2). The result of the above procedure is a data set consisting of a [parameter $\mathrm{x}$ location bin] matrix for every measuring day. A summary of measuring days selected for YOGAM, including meteorological conditions, is given in Table 3. Although the YOGAM campaigns also included measurements made during spring and summer 2001, they were not used for ANOVA and PCA due to problems with SMPS and DC measurements (high signal scattering due to sampling problems and calibra- tion problems, respectively). Summer data for the rest of the measured parameters $\left(\mathrm{N}_{\mathrm{tot}}, \mathrm{N}_{\mathrm{bkg}}, \mathrm{CO}\right)$ are however considered on other occasions in this paper and are mentioned in the specific context.

\section{ANOVA tests - does day-to-day variation exceed spa- tial variation?}

In our previous case study (Bukowiecki et al., 2002) we showed that on a specific measuring day the background particle number concentration in our testing area differed by up to more than one order of magnitude between urban and rural 
Table 3. Overview over the YOGAM measuring days discussed in this study. Summer 2001 data (5 measuring days) were not used for this study except for CO due to problems with SMPS and DC measurements. Temperature and global radiation represent daily averages plus standard deviation of the day-time mean (temperature) and 95\% percentile (global radiation) values measured with the mobile laboratory

\begin{tabular}{|c|c|c|c|c|}
\hline & Date & Day type & Temperature $\left({ }^{\circ} \mathrm{C}\right)$ & Global Radiation $\left(W m^{-2}\right)$ \\
\hline \multirow{5}{*}{ 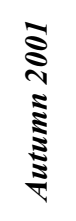 } & 11.10 .01 & Weekday & $12.9 \pm 2.6$ & $300 \pm 114$ \\
\hline & 14.10 .01 & Sunday & $15.6 \pm 3.0$ & $320 \pm 92$ \\
\hline & 31.10 .01 & Weekday & $14.4 \pm 1.7$ & $214 \pm 132$ \\
\hline & 05.11 .01 & Night & $4.6 \pm 1.0$ & - \\
\hline & 06.11 .01 & Weekday & $5.9 \pm 1.1$ & $138 \pm 92$ \\
\hline \multirow{5}{*}{ 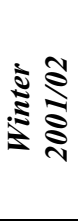 } & 28.01 .02 & Weekday & $9.9 \pm 1.1$ & $214 \pm 102$ \\
\hline & 29.01 .02 & Weekday & $5.1 \pm 2.1$ & $156 \pm 52$ \\
\hline & 29.01 .02 & Night & $1.2 \pm 2.0$ & - \\
\hline & 30.01 .02 & Weekday & $6.8 \pm 3.3$ & $218 \pm 90$ \\
\hline & 03.02 .02 & Sunday & $8.6 \pm 3.1$ & $254 \pm 100$ \\
\hline \multirow{9}{*}{ 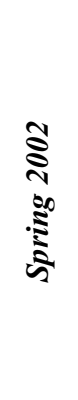 } & 22.04 .02 & Weekday & $10.7 \pm 2.8$ & $510 \pm 130$ \\
\hline & 23.04 .02 & Weekday & $13.1 \pm 2.3$ & $528 \pm 136$ \\
\hline & 25.04 .02 & Weekday & $12.2 \pm 2.9$ & $480 \pm 180$ \\
\hline & 26.04 .02 & Weekday & $14.5 \pm 1.6$ & $314 \pm 214$ \\
\hline & 15.05 .02 & Weekday & $15.5 \pm 2.5$ & $626 \pm 90$ \\
\hline & 16.05 .02 & Weekday & $18.8 \pm 3.3$ & $612 \pm 96$ \\
\hline & 17.05 .02 & Weekday & $22.1 \pm 2.8$ & $624 \pm 80$ \\
\hline & 30.05 .02 & Night & $10.0 \pm 2.0$ & - \\
\hline & 02.06 .02 & Sunday & $18.0 \pm 2.0$ & $640 \pm 100$ \\
\hline
\end{tabular}

areas. Taking all the data from the whole year into account, the question arises how this urban/rural variation is quantitatively related to the day-to-day variation due to different meteorological conditions in the Zürich area. Figure 2 shows a date vs. location contour plot for the $5 \%$ percentile (background) values of the total particle number concentration. It is clearly seen that rural and urban regions, but also locations influenced by heavy traffic, show different levels throughout the year (horizontal stripes). However, there are days/periods in which the overall particle background concentration is much higher than during other days or periods, exceeding the regional variation. To better examine the influence of both daily weather conditions and local pollution characteristics on the measured parameters, Fig. 3 shows box plots for the measured levels of $\mathrm{N}_{\mathrm{bkg}}, \mathrm{N}_{\mathrm{tot}}, \mathrm{N}(80-140), \mathrm{N}(<30)$, active surface area and $\mathrm{CO}$, separated both by date (daily averages over all locations) and location (location bin averages over all dates). Before interpreting the plot, analysis of variance (ANOVA) was performed for additional quantification, i.e. to examine whether the variation of the above average values was significant for date and location. A two-way factorial layout with replicates was applied, using the SPLUS 6.0 software (Insightful Inc., Seattle, Washington) with variables that were transformed to be normally distributed according to Table 2 (see Chambers and Hastie, 1992; Voss, 2000). F-values were calculated for both factors (date and location) to test the null hypothesis. For an acceptable null hypothesis, F-values are close to 1 and indicate that the variance between different groups of concentration levels (e.g. the variance of the daily averages) is approximately equal to the variance within all the individual concentration levels (i.e. the variance of the entire sample population). $\mathrm{F} \gg 1$ thus indicates that the variance (i.e. the effect on the signal) between the level groups is significantly larger than the sample population variance.

The ANOVA showed that for all the selected parameters the variance both in date and location was significant (on a 0.01 level for F-statistics, probability $\mathrm{p}(\mathrm{F}) \ll 0.001)$. Furthermore, both ANOVA and the box plots in Fig. 3 reveal that for $\mathrm{N}_{\mathrm{bkg}}\left(\mathrm{F}_{\text {date }}=73.5\right.$, $\left.F_{\text {location }}=4.21\right), \quad \mathrm{N}_{\text {tot }}\left(\mathrm{F}_{\text {date }}=265, \quad \mathrm{~F}_{\text {location }}=21.7\right)$, the active surface area $\left(\mathrm{F}_{\text {date }}=197, \mathrm{~F}_{\text {location }}=17.5\right)$ and $\mathrm{N}(80-140)$ $\left(F_{\text {date }}=152, F_{\text {location }}=25\right)$ the variation in date exceeded the variation in location. For these parameters, the ANOVA model also quantitatively confirms the qualitative finding drawn from Fig. 2. For $\mathrm{N}(<30)\left(\mathrm{F}_{\text {date }}=36.0, \mathrm{~F}_{\text {location }}=16.7\right)$ and $C O\left(F_{\text {date }}=19.5, F_{\text {location }}=11.4\right)$, the spatial variation is more similar to the day-to-day variation. It is suspected that this is due to the regularly observed formation of primary ultrafine particles with a short lifetime (see Introduction) in heavy-trafficked areas, and due to the long atmospheric lifetime of CO, respectively, as it will also be further discussed in Sects. 4 and 5. 


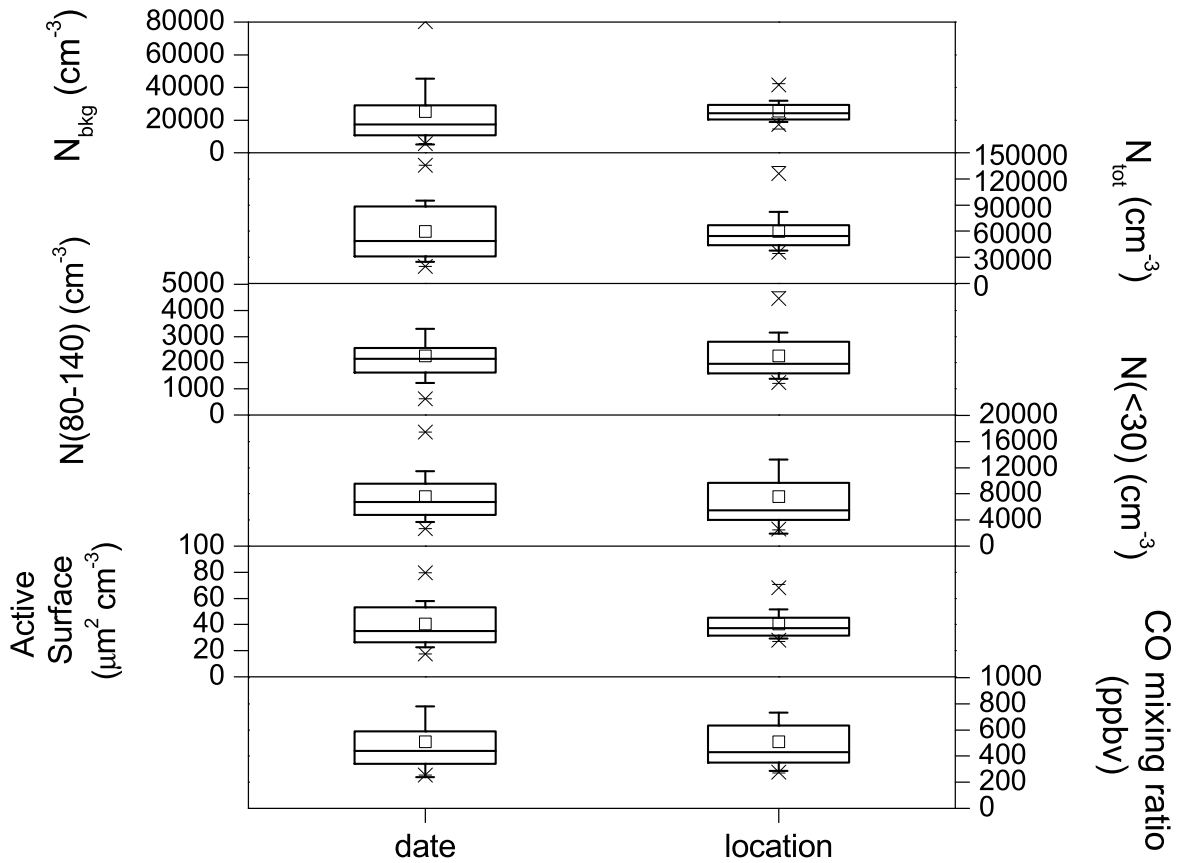

Fig. 3. Box plots for the measured concentration levels of $\mathrm{N}_{\mathrm{bkg}}, \mathrm{N}_{\text {tot }}, \mathrm{N}(80-140), \mathrm{N}(<30)$, active surface area and CO during the YOGAM days (see Table 3), separated both by date (daily averages over all locations) and location (location bin averages over all dates). Box $=$ median, $25 \%$ percentile, $75 \%$ percentile; $\square \equiv$ mean; $\mathrm{x} \equiv$ minimum/maximum. Error bars represent standard deviation.

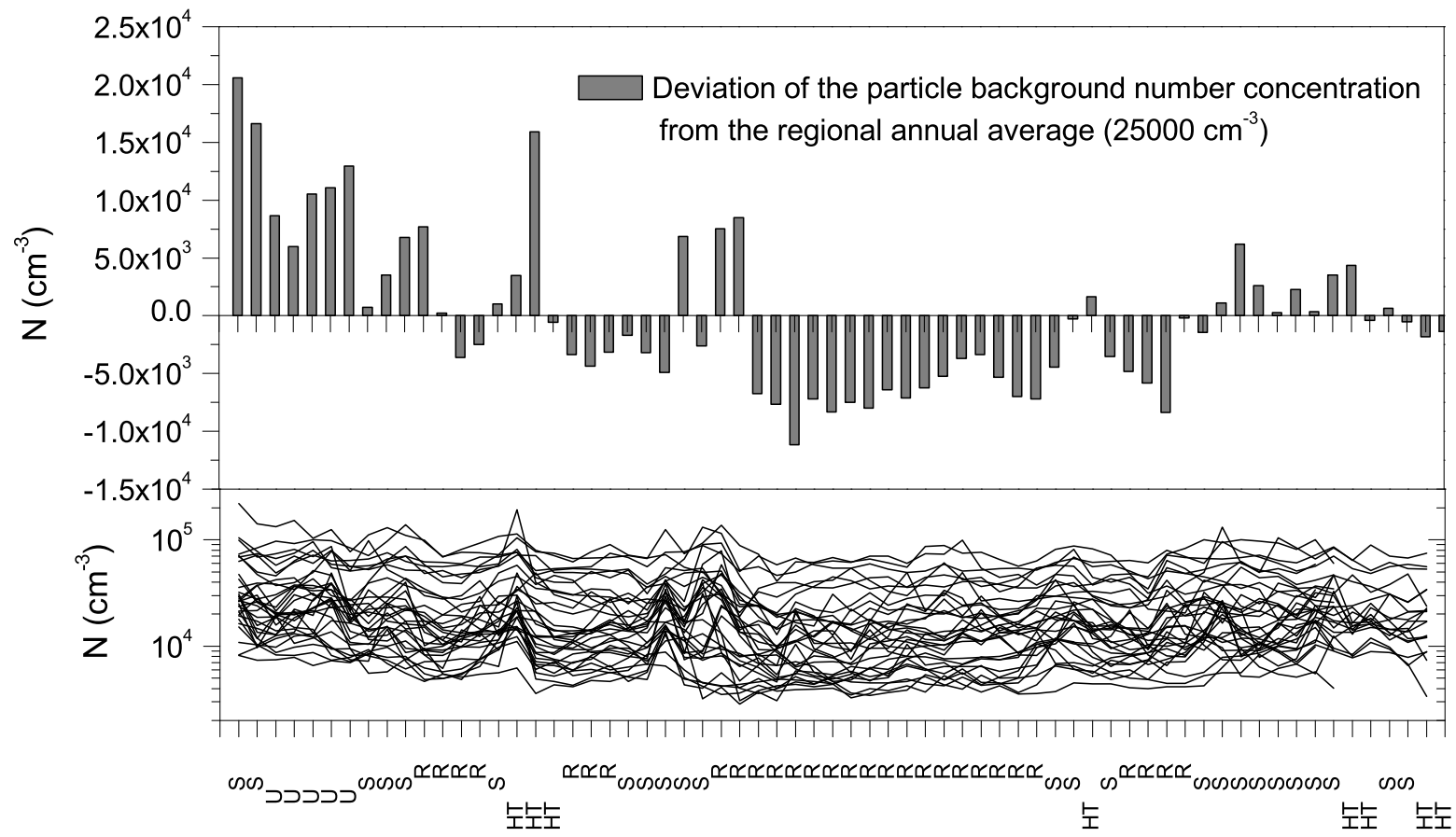

Fig. 4. Annual regional average of the particle background number concentration in the Zürich area during YOGAM. The deviation from the annual regional average $\left(25000 \mathrm{~cm}^{-3}\right)$ is shown for every location bin (upper panel), plus the background number concentration measured along the YOGAM route on the individual days (bottom panel, logarithmic scale). S=Suburban, U=Urban, R=Rural and HT=Heavy traffic areas. 
Conclusively, Fig. 4 illustrates the variation of the selected pollutants in the YOGAM area. The upper plot shows the deviation of the particle background number concentration from the annual average in the YOGAM area. Depending on the daily weather condition, the curve is shifted up or down, maintaining a similar shape (Fig. 4, lower panel). On average, a clear differentiation for urban, rural and heavy- trafficked areas is recognized on a per-route base. As shown in the bottom plot, the signal scattering (i.e. the absolute day-today variance) is basically constant for all location bins. This is also supported in the ANOVA by an insignificant interaction between the date and location factor $(\mathrm{p}(\mathrm{F}) \gg 0.05$ for all parameters).

Before analyzing seasonal averages of the above parameters we investigated how well the measuring days selected during YOGAM could be considered as representatives for the corresponding seasons, since the meteorology of the selected days possibly differed from the seasonal average and rainy days were entirely excluded from the YOGAM measurements. From two official monitoring sites that are operated by the Zürich city authorities and located at different locations in downtown Zürich, PM10, PM2.5 and CO values were available for comparison with the YOGAM mobile measurements. In Fig. 5, PM10, PM2.5 and CO mean values (weighted per day) estimated from mobile laboratory measurements in downtown Zürich (typically $15 \mathrm{~min}$ in the morning and one hour at noon on every measuring day, plus one $24-\mathrm{h}$ period in every season) are compared to the corresponding parameters measured at the stationary measuring sites. For mobile YOGAM data, PM10 and PM2.5 were estimated from V10 and V2.5, respectively, assuming a particle density of $1.7 \mathrm{~g} \mathrm{~cm}^{-3}$. This is only a rough approximation, since bulk material density, particle shape and ambient humidity have a large influence on the exact value (Hand and Kreidenweis, 2002). Main characteristics seen in Fig. 5 are:

- Stationary measurements, seasonal (24-hour) means vs. YOGAM days (24-hour): For PM10 (and also the available PM2.5 data), the selection of measuring days was only significantly representing the seasonal 24-hour mean for summer, while the selection of campaign days led to significantly higher seasonal median values for the other seasons (especially in autumn). For CO, the selection of days was not significantly representative for the seasonal 24-hour mean for any of the seasons, although the mean values are similar for summer and spring.

- Stationary measurements, YOGAM 24-hour means vs. YOGAM midday means: The measured mean values were significantly different from each other for most of the parameters and seasons, reflecting that a short midday episode is in most cases not representative for the entire diurnal variation, which is strongly influenced by rush hour or nighttime stagnation episodes). For PM10

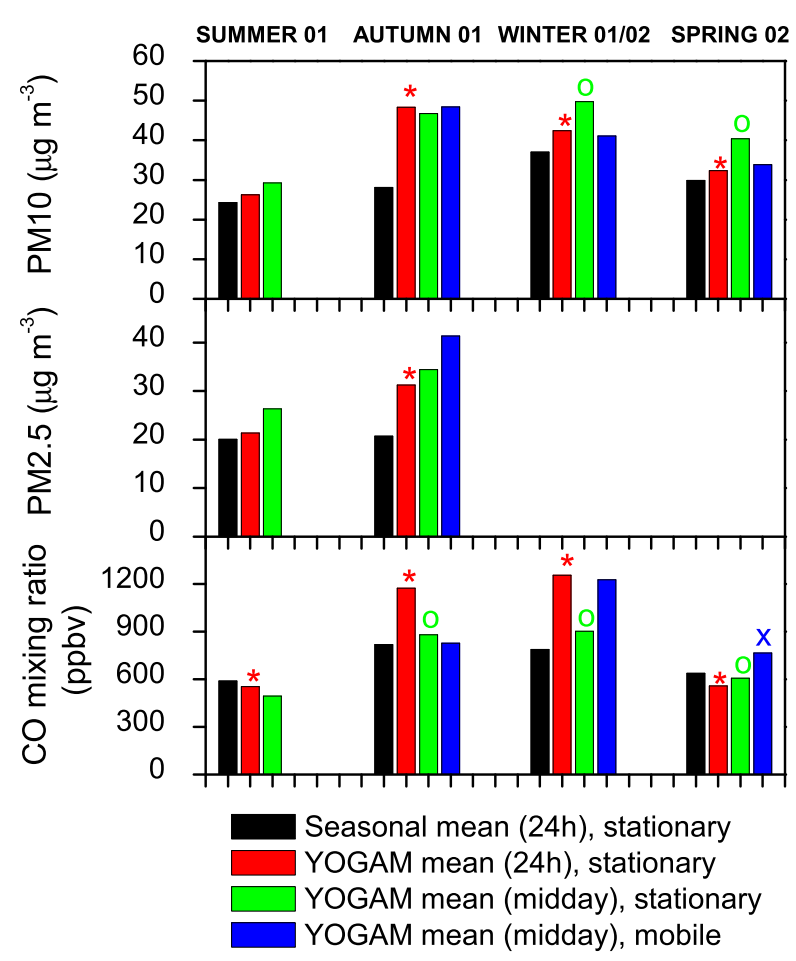

Fig. 5. Comparison of PM10, PM2.5 and carbon monoxide measurements made by the YOGAM mobile laboratory with measurements performed by the official Zürich city monitoring program at two Zürich downtown locations. Mean values are shown here, which did not relevantly differ from the corresponding median values. On each YOGAM day, the mobile laboratory was used for short-term stationary measurements at Zürich-Wiedikon, where also one of the two official monitoring sites is located. PM10 and PM2.5 for the YOGAM mobile measurements were estimated from V10 and V2.5 using a particle density of $1.7 \mathrm{~g} \mathrm{~cm}^{-3}$ (see text). A one-way ANOVA was performed to find significant differences between the considered mean values. A star above the bars denotes a significant difference (on a 0.05 level) between the 24-hour seasonal mean and the 24-hour mean of the YOGAM days. Equally, a circle denotes a significant difference between the YOGAM 24-hour and midday means, while an " $x$ " denotes a significant difference between the midday stationary and mobile lab measurements.

(and PM2.5) the midday means were higher than the 24-hour means, while mean diurnal CO concentrations were lower during midday episodes.

- Stationary vs. mobile measurements, comparison of YOGAM midday data: The (partially parked) mobile YOGAM mean data for CO, PM10 and PM2.5 did not statistically differ from the corresponding stationary midday means (except for spring), although the mean values appear considerably different in the plots. This is due to the smaller sampling population for the midday mean values, yielding a larger variance and a smaller $\mathrm{F}$-value in F-statistics (see above). 

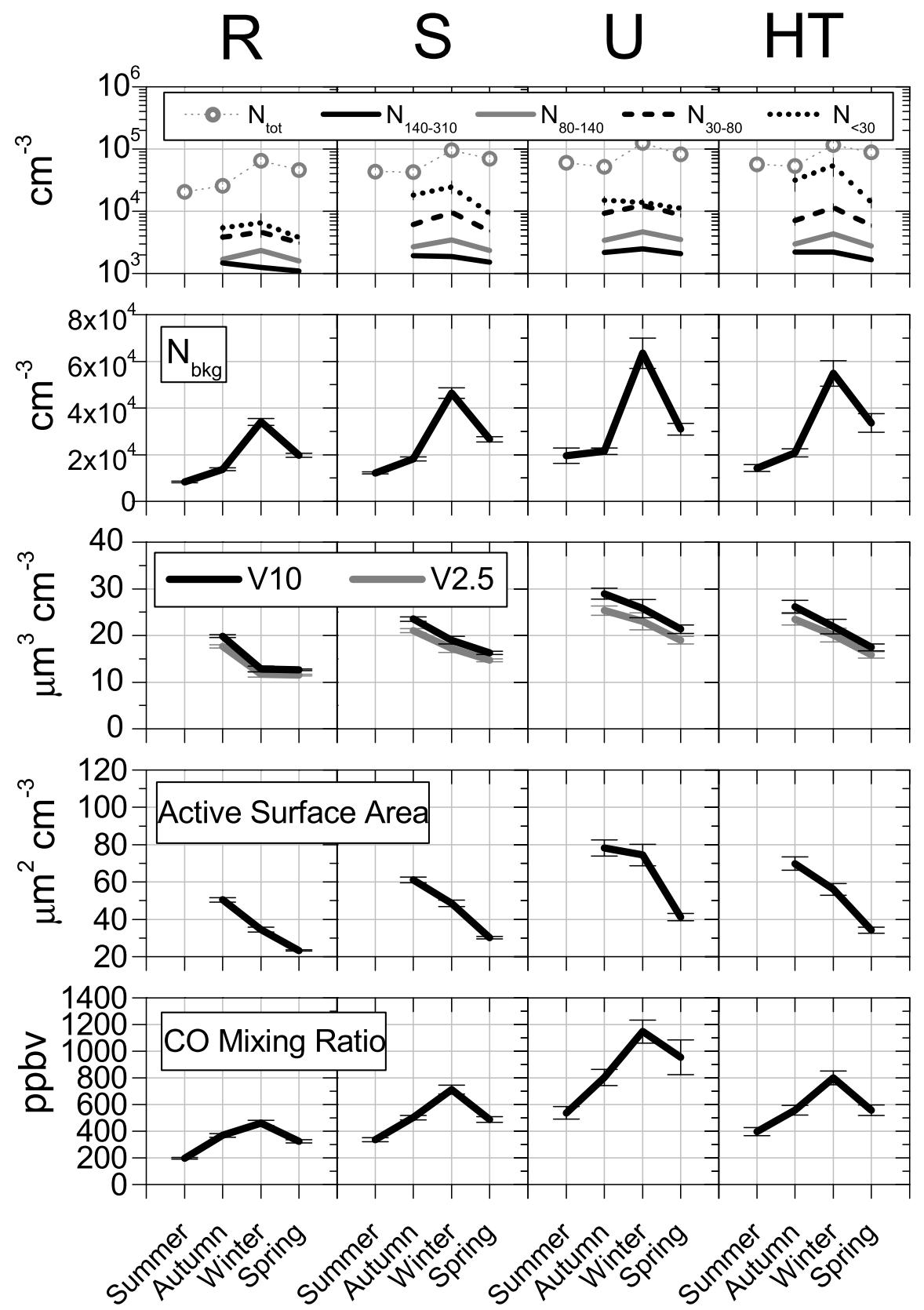

Fig. 6. Seasonal variation of $\mathrm{N}_{\text {tot }}, \mathrm{N}_{\text {bkg }}, \mathrm{N}(<30), \mathrm{N}(30-80), \mathrm{N}(80-140), \mathrm{N}(140-310)$, V2.5, V10, active surface and carbon monoxide, resolved by location category (R: rural, S: suburban, U: urban, HT: heavy-traffic areas, see Table 1 and Fig. 1). Mean values are shown, with bars representing one standard error of mean. Due to SMPS and DC measurement problems no summer data are available except for $\mathrm{N}_{\text {tot }}$, $\mathrm{N}_{\mathrm{bkg}}$ and CO.

Overall, the selected YOGAM measuring days overestimated seasonal means during 2001 and 2002, especially for autumn and winter. This possibly reflects the fact that only days without rain were selected for YOGAM measurements. Given the complex measuring situation, the midday Zürich downtown mobile measurements agreed reasonably well with the corresponding stationary measurements. Fig- ure 6 shows the seasonal variation of the above parameters (plus V10, V2.5, N(30-80) and $\mathrm{N}(140-310)$ ), resolved by location category (rural, suburban, urban and heavy-traffic areas) as defined in Table 1. Roughly, $\mathrm{CO}$ and most number based aerosol parameters $(\mathrm{N})$ on the one hand and V10, V2.5 and the active surface area on the other hand show similar seasonal trends. According to the estimation of seasonal 


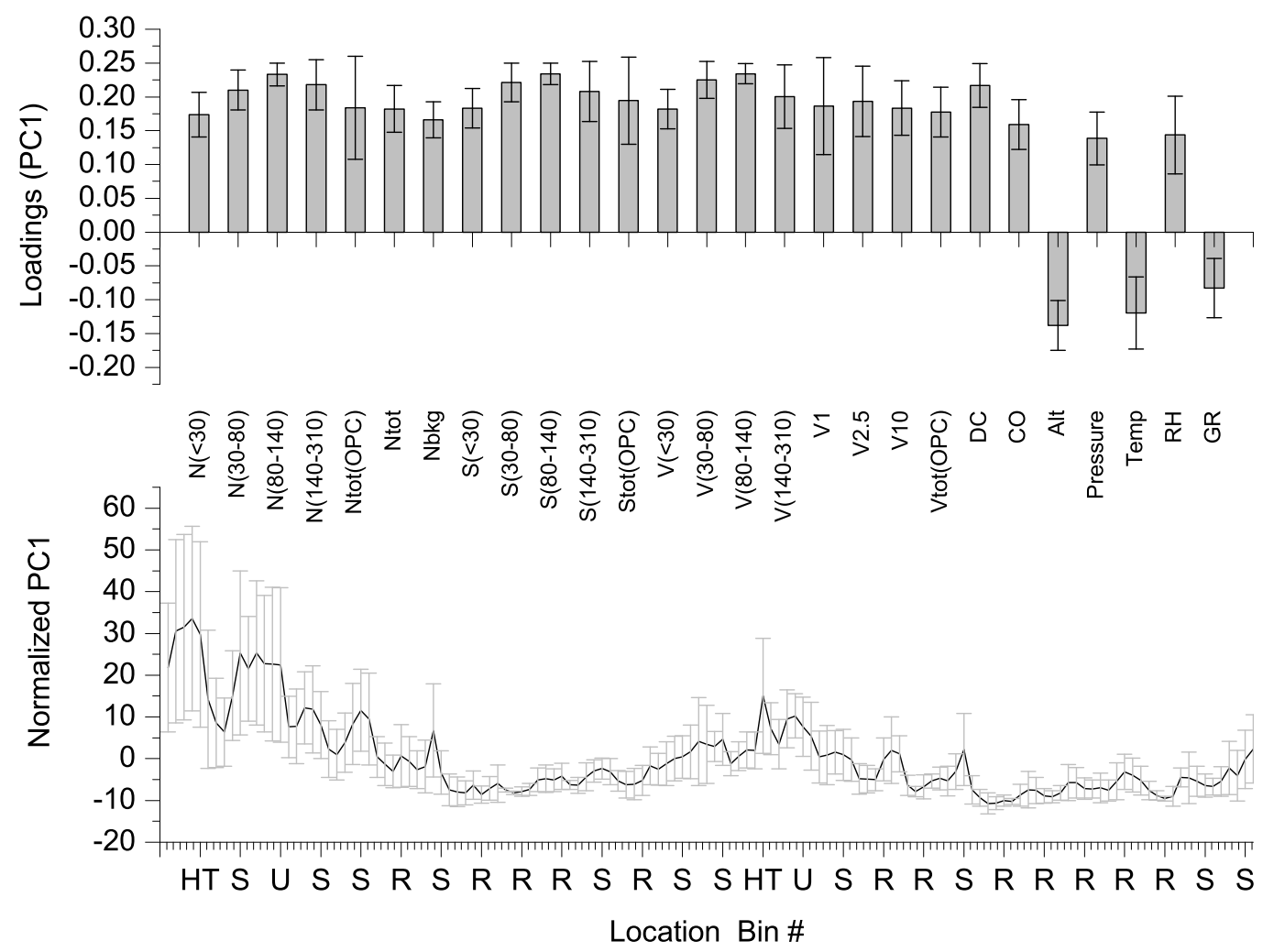

Fig. 7. Normalized first principal component PC1 (bottom graph) and the corresponding loading pattern (top graph). The average plus standard deviation of the individual days is shown and thus represents an annual average. Variable names and location classifications are given according to Tables 1 and 2 .

representation described in the previous paragraph, winter data are too high for the first group $(\mathrm{CO}, \mathrm{N})$, while the second group (V10, V2.5, active surface area) primarily overestimates the autumn data. On average, rural (R) and suburban (S) areas showed lower concentration levels than urban (U) and heavy-traffic (HT) regions for all considered parameters except $\mathrm{N}(<30)$. Overall, higher levels were found during autumn and winter for the size range $D<310 \mathrm{~nm}$, for V10, 2.5 and for the active surface area. In contrast, winter and spring dominated the seasonal variation of $\mathrm{N}_{\text {tot }}, \mathrm{N}_{\mathrm{bkg}}$ and $\mathrm{CO}$.

\section{PCA - exploratory data analysis}

Principal component analysis is first of all a data reduction technique (see e.g. textbooks by Jolliffe (1986) or Mardia et al. (1979)). Figuratively, it extracts the directions in which a cloud of data points is maximally stretched, i.e. has a maximal variance. The most relevant information of the data set ( $J$ variables with $K$ observations) is contained in these directions (i.e. principal components, in the following termed PCs). The PCs represent orthogonal and therefore independent linear combinations $\mathrm{PC}_{i}$ of the $J$ original variables $v$ :
$\mathrm{PC}_{(i)}=\sum_{j=1}^{J-1} b_{i j} \cdot v_{j}$,

where $b_{i j}$ are the component loadings and indicate how strongly a specific original variable $v_{j}$ contributes to $\mathrm{PC}_{i}$ and $v_{j}$ is the original variable. PCs are found by calculating the eigenvectors and corresponding eigenvalues of the correlation matrix formed by the input data. The projection of the original data on the eigenvectors defines the PCs, and the eigenvalue of every eigenvector indicates the contribution of the specific PC to the total data set variance. By definition, there are $J-1$ principal components, with the first ones containing the most relevant information. Taking only these PCs, the original data set can be stored and compressed with a lower amount of variables, and the original data can be restored with only a minor loss of information.

For the YOGAM data, PCA was individually performed for the [location bin $\times$ measured parameter] matrix of every measuring day showing no data gaps, using the SPLUS 6.0 software. This strategy of analyzing single days individually was selected because an annual analysis of all the data is already covered by the previous section and would therefore 
possibly yield redundant information. The goal was rather to obtain individual "footprints" for every day, telling more about the influence of e.g. meteorological conditions on the spatial and daily variation of the pollutants. From the input matrix, the correlation matrix was calculated. Both original data and data transformed to normality (see Table 2) were tested as input for PCA. No significant changes in the loading pattern were observed, so we decided to use the original data to avoid interpretation artifacts due to distortion of the original data. The signal-to-noise ratio was larger than 3 for all variables, so no down-weighing of noisy variables had to be taken into account (Paatero and Hopke, 2003). A further issue regarding our input data is the fact that although several parameters in our input matrices are not in linear relationship, they are in a square relationship to each other (especially the $\mathrm{N}, \mathrm{S}$ and $\mathrm{V}$ variables). Testing the influence of the number of dependent parameters in the input matrix on the PCA results again showed that the PCs and their loading patterns did not relevantly change. A change occurred however in the relevance of the individual PCs, i.e. the eigenvalues of the components decreased with a decreasing number of dependent parameters. With a minimal set of parameters, different criteria for evaluating the relevance of PCs (see PCA textbooks) suggest that mainly the two first PCs are relevant. Overall, it was therefore decided to use the full set of variables for the further qualitative analysis of the first two principal components. With this analytical design, the first PC explained $60 \pm 5 \%$ of the total variance, whereas the second PC accounted for $15 \pm 5 \%$. Respective values for the further PCs 3 and higher were lower than $10 \%$.

Standardized component loadings $c_{i j}$ (Eq. 2) and the standardized values of PCs, $x_{i j k}$, (Eq. 3) are the most useful parameters for a qualitative PCA analysis:

$c_{i j}=\frac{b_{i j}}{\sqrt{E V_{i}}}$

$b_{i j}$ : loading value of $\mathrm{PC}_{i}$ for variable $v_{j} ; E V_{i}$ : eigenvalue of $\mathrm{PC}_{i}$.

$x_{i j k}=\sum_{j=1}^{J-1} \frac{v_{j}(k)-\overline{v_{j}(k)}}{s\left(v_{j}\right)} \cdot c_{i j}$

$v_{j}(k): k$-th value of variable $v_{j} ; s\left(v_{j}\right)$ : standard deviation of variable $v_{j}$.

Figure 7 shows the annual average of the first principal component, along with its loading pattern. Obviously, the loading pattern for the first component shows relatively little variation throughout the year (see standard deviation bars). All loadings except for global radiation, altitude and temperature have positive values. The parameters that are contributing most to the first $\mathrm{PC}$ are those in the middle of the considered size spectrum, i.e. N, S, V(80-140) or N, S, V(140310), as well as CO and the active surface area. At the same time they showed a minimal contribution to PC2 (loading values $<20 \%$ of the maximum PC2 values). This suggests

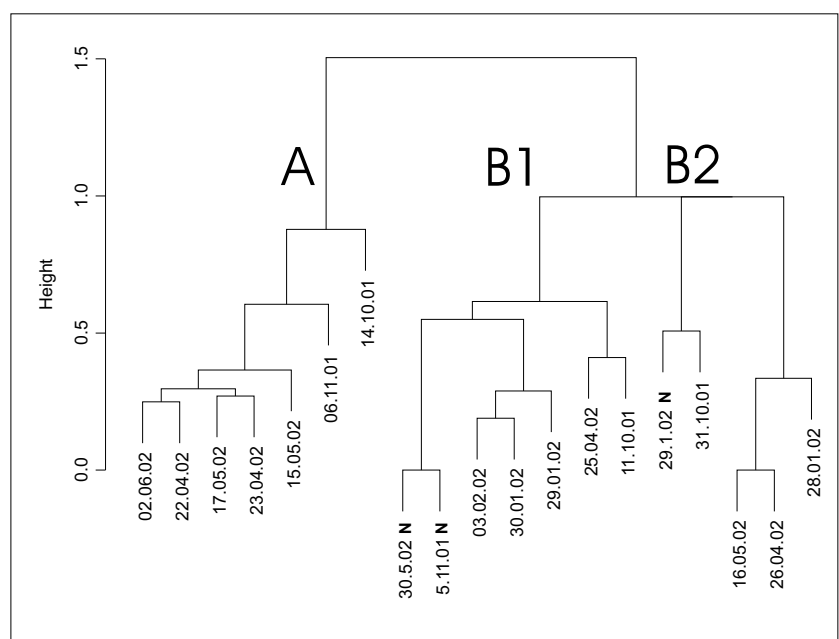

Fig. 8. Cluster analysis hierarchy tree for the 19 PC2 loading patterns obtained by individual PCA for every YOGAM measuring day. Every individual loading pattern contained 12 parameters (see text). A divisive clustering algorithm based on euclidean distances was used. A, B1 and B2 represent main branches, splitting the data into three categories.

that this component represents a general degree of pollution. The standardized PC1 (lower graph in Fig. 7) shows high values in urban regions and regions with heavy traffic and low values in rural areas far away from anthropogenic activity. This leads to the conclusion that the largest variation in our daily data sets is caused by the degree of anthropogenic influence on the respective measuring locations. In contrast to PC1, PC2 showed no uniform loading pattern throughout the year. Since N, S, V(80-140) or N, S, V(140-310) hardly contribute to PC2 (see above), other factors than anthropogenic influence had to be found. To reveal similarities in the loading patterns of $\mathrm{PC} 2$, a cluster analysis was performed. Both for PC1 and PC2 the loading values of N, S and V differed by less than $10 \%$ within the particle size ranges $7-80 \mathrm{~nm}$, $80-310 \mathrm{~nm}$ and $310 \mathrm{~nm}-10 \mu \mathrm{m}$. Therefore, average values $A_{7-80}^{\mathrm{N}, \mathrm{S}, \mathrm{V}}, A_{80-310}^{\mathrm{N}, \mathrm{S}, \mathrm{V}}$ and $A_{310-10000}^{\mathrm{N}, \mathrm{S}, \mathrm{V}}$ were used for cluster analysis of the PC2 loadings. The input for the cluster analysis was a [parameter $\mathrm{x}$ date] matrix consisting of the PC2 loading patterns, with the 12 parameters $\mathrm{CO}$, active surface area, $\mathrm{N}_{\text {tot }}, \mathrm{N}_{\text {bkg }}, A_{7-80}^{\mathrm{N}, \mathrm{S}, \mathrm{V}}, A_{80-310}^{\mathrm{N}, \mathrm{S}, \mathrm{V}}$ and $A_{310-10000}^{\mathrm{N}, \mathrm{S}, \mathrm{V}}$, altitude, pressure, temperature, relative humidity and global radiation for the 19 YOGAM measuring days (matrix dimension 12 $\times$ 19). A hierarchical tree with euclidean distances (Fig. 8) was obtained using a divisive clustering algorithm (Kaufman and Rousseeuw, 1990). A clear split into two main branches ( $A$ and $B$ ) is seen, while branch $B$ is divided in two major sub-branches (B1 and B2) on the second highest hierarchical level. Within these three categories (A, B1 and B2) we searched for meteorological/geographical variables that were different in the three individual cluster categories. Figure 9 
shows that despite a few outlier days global radiation seems to be a main divider for category $\mathrm{A}$ and $\mathrm{B}$, and that the wind speed at high altitudes is significantly split by all three categories ( 0.05 level significance in F-test statistics). In contrast, temperature is statistically only insignificantly different, although temperatures appear to be highest in category $\mathrm{A}$ and lowest in category B1. In categories B1 and B2 the main wind direction was SW (80\%), while the prevailing wind direction for category A was NE and SW in an approximately 1:1 ratio. Concluding this section, the following statements and questions arise from the PCA and cluster analysis:

- Within one day, the distance to anthropogenic pollution sources caused the largest variation $(65 \%)$ in the measured pollutant parameters. This contribution to the total data variance was in all cases larger than influences from meteorology (on a one-day base). In the selected area, most of the locations that are least influenced by anthropogenic activity are located at higher altitudes.

- Beside anthropogenic activity, meteorological conditions are suspected to explain further $15 \%$ of the total pollutant variation. Namely differences in global radiation and in the wind speed at high altitudes split the YOGAM days into different categories, each possibly reflecting a particular meteorological situation. In this case it is expected that particle number size distributions will show differences for these individual categories.

\section{Using PCA results as input for further data analysis}

As stated in the previous section, anthropogenic air pollution can statistically be assigned to high levels of particles in an intermediate size range ( $80-310 \mathrm{~nm})$ and high CO levels. For further analysis, this knowledge was then used to have a more specific look into the original data set. Indeed, it is already known from gas phase chemistry that $\mathrm{CO}$ is a good indicator for anthropogenic activity. Furthermore, we already showed in Bukowiecki et al. (2002) that the particle number concentration in the size range $80-140 \mathrm{~nm}$ is strongly connected to anthropogenic activity. PM10 or PM2.5 in areas surrounding an urban region are further parameters often discussed in this context (see Introduction). To carry on the discussion of the previous section's findings, the YOGAM database (see Sect. 2) was therefore used to classify data in the two following ways.

\subsection{Location-dependent pollution}

For all database entries (i.e. 1 morning and 1 afternoon value per date and location, except location bins 1-9) of $\mathrm{N}(80-140)$, V2.5 (representing PM2.5) and CO, the percentile within the individual parameter was calculated. Categorizing these percentiles by location and parameter yielded an average percentile for every location and every parameter.

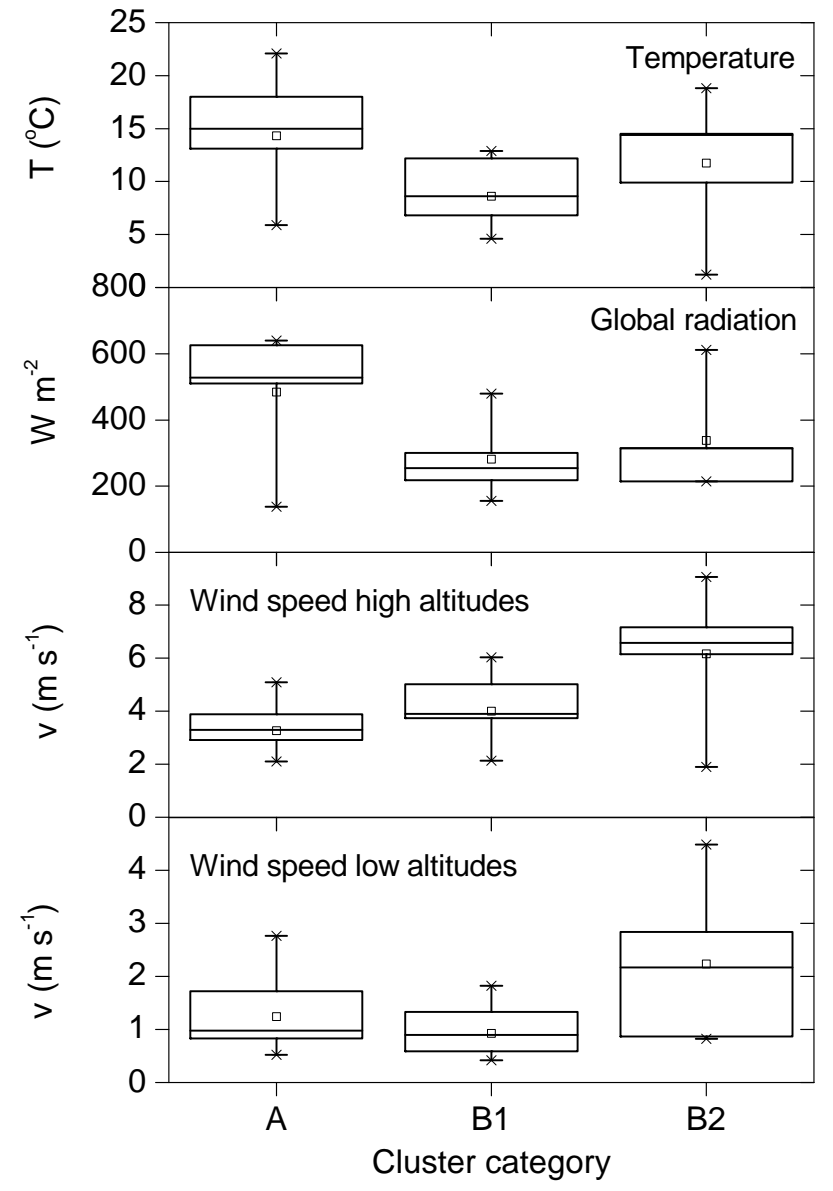

Fig. 9. Meteorological daily average parameters (temperature, global radiation, wind speed at high/low altitudes) split into cluster categories A, B1 and B2. Box = median, $25 \%$ percentile, $75 \%$ percentile; $\square \equiv$ mean; $\mathrm{x} \equiv$ minimum/maximum. Whiskers represent $5 / 95 \%$ percentiles. Wind speed for high altitudes was calculated by averaging daily data from meteorological monitoring stations M1 (850 $\mathrm{m}$ a.s.1.) and M2 (1130 $\mathrm{m}$ a.s.1.) (see Fig. 1), while wind speed for low altitudes represents corresponding average data from stations M3-M7.

Figure 10 shows this average percentile for every location bin and parameter, in chronological order according to the YOGAM route. Additionally, the altitude profile is shown. It is confirmed that most of the locations that are least influenced by anthropogenic activity are located at higher altitudes. The only exceptions are locations influenced by busy main roads. The relationship between the percentiles and the inverse altitude is almost linear for all three parameters $\left(\mathrm{R}^{2}=0.6 \pm 0.1\right)$.

\subsection{Event-based pollution}

To study the influence of meteorological parameters, a classification of the individual measurements (in the following termed events), rather than a classification per location bin was considered to be reasonable. Again, the percentile of 


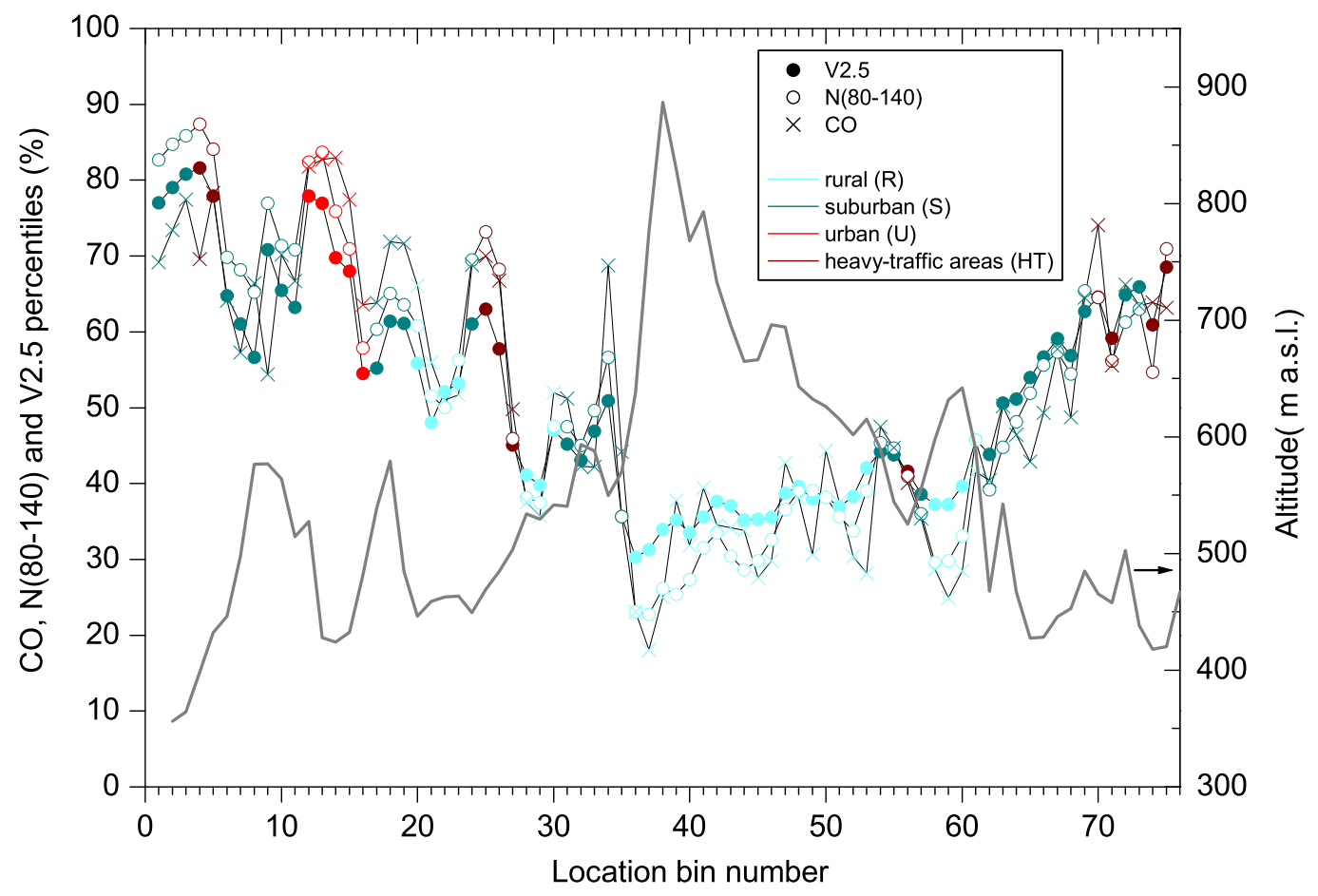

Fig. 10. Location-attributed average percentiles for pollution by CO, N(80-140) and V2.5 (see text). The x-axis represents the YOGAM route in chronological order and shows classifications according to Table 1. Additionally, the altitude profile of the YOGAM route is shown.

every single value was calculated individually for $\mathrm{N}(80-$ 140), V2.5 and CO. In contrast to above, the average of the percentiles over the three parameters was then formed for every date and location in the database. These average percentiles per event were assigned to one of 5 categories: category 1 included average percentile values of $0-20 \%$, category $220-40 \%$, category $340-60 \%$, category $460-80 \%$ and category $580-100 \%$. In this way, high-pollution events would fall into category 5 , while clean-air events were assigned to category 1 . Figure 11 shows annual mean and median SMPS particle number size distributions for the individual categories. There is a remarkable difference between the median and the mean distributions especially for category 5 , indicating that extreme situations within this category strongly influence mean distributions. Here, extraordinarily high number concentrations of ultrafine particles are found, which were regularly observed in the morning hours on a route stretch near a busy freeway (location bin numbers 4 and 5 in Table 1). This level of primary ultrafines is typical for freeways (Kittelson et al., 2001; Zhu et al., 2002) and is much larger than for other, non-freeway urban conditions that statistically were more frequent during YOGAM. This is also reflected in the median size distribution, which is less influenced by freeway situations. The trend from categories 1 to 5 shows, beside an increase in the integrated number concentration and the number concentration in the combustion aerosol accumulation mode, an especially noticeable in- crease in ultrafine number concentration. This confirms that the formation of primary ultrafines was enhanced in situations of high anthropogenic (and especially traffic-related) air pollution. There is however no evidence from these data that a large number concentration of accumulation mode particles, which shortens the lifetime of ultrafine particles due to higher coagulation rates, suppresses nucleation of primary ultrafines.

Figure 12 shows temperature-resolved mean and median number size distributions for category 5 and confirms the previous findings in literature stating that the formation of primary ultrafine particles is enhanced at cold temperatures (Abdul-Khalek et al., 2000), as it is seen both in mean and median number size distributions. The differences in the mean and median distributions can be assigned to the same reasons as discussed for Fig. 11. Figures 13 and 14 show particle number size distributions resolved by cluster categories A, B1 and B2 (see Sect. 4) for the pollution categories 5 and $(1,2)$, respectively. Additionally, the size distributions are split into morning and afternoon cases. OPC size distributions are included in graphs. The slight discontinuities in the combined SMPS and OPC number distributions are likely to result from the fact that in the OPC the individual particles are classified according to their light scattering behavior, which depends on the particle size, morphology and refractive index. Since the OPC was calibrated with spherical Latex particles, the observed shift towards smaller 


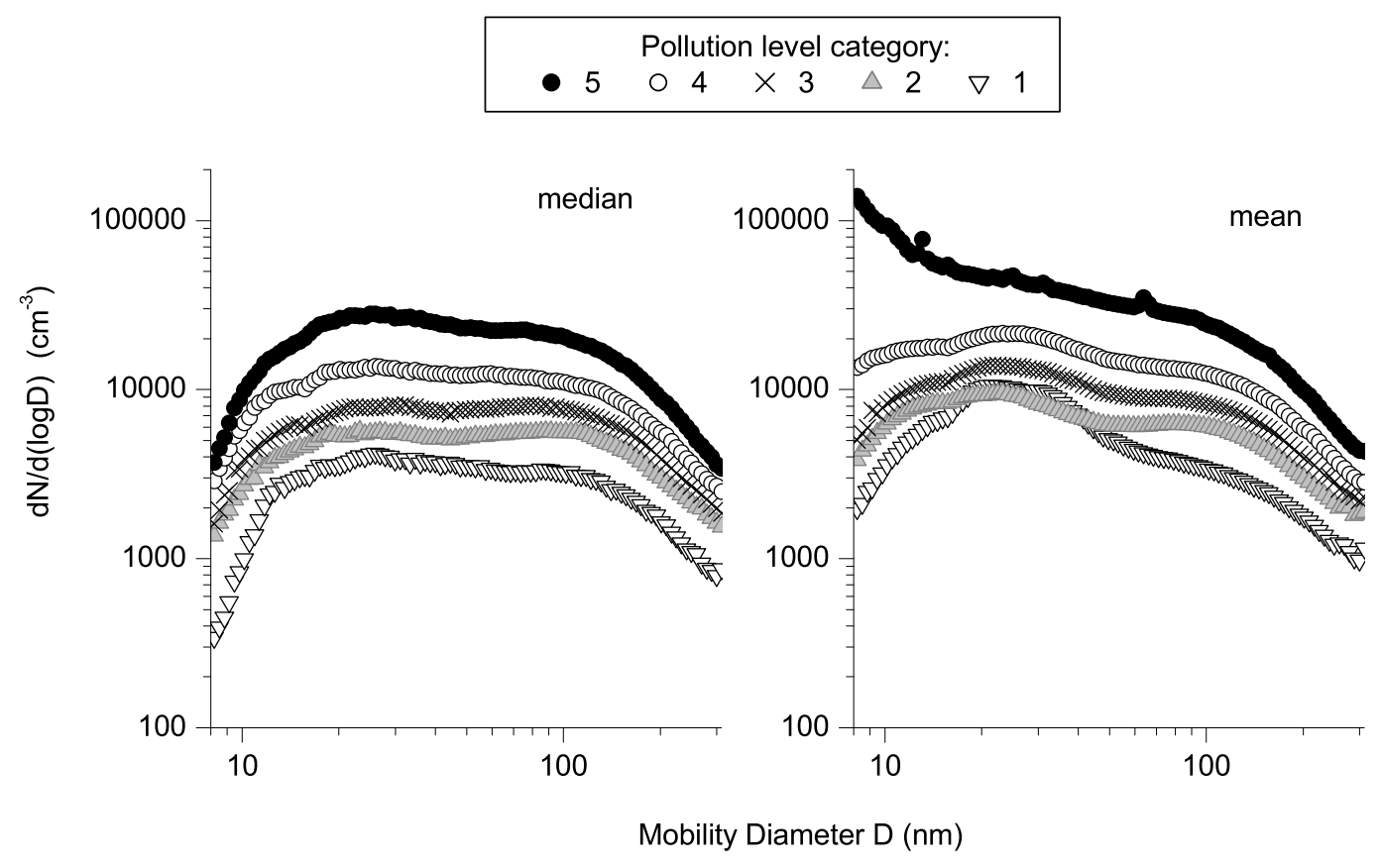

Fig. 11. SMPS number size distributions for the event-based pollution categories defined in Sect. 5.2. Both median and mean distributions are shown. The distributions are based on the whole-year YOGAM data set.

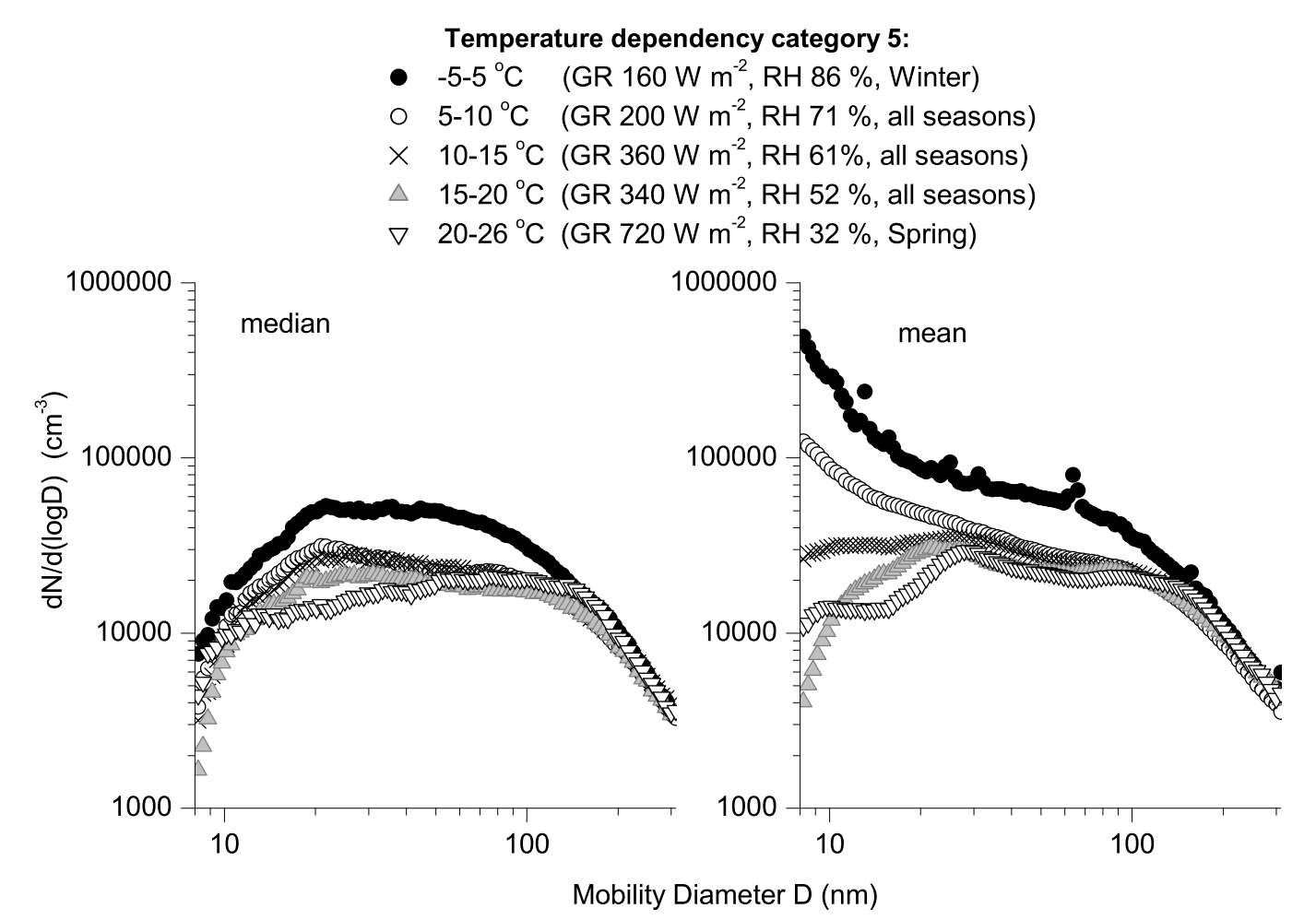

Fig. 12. Temperature-resolved SMPS number size distributions using all YOGAM database entries assigned to pollution category 5 (see text). Both median and mean distributions are shown. The average number of individual distributions per temperature category is $150-200$. GR: Global radiation. 


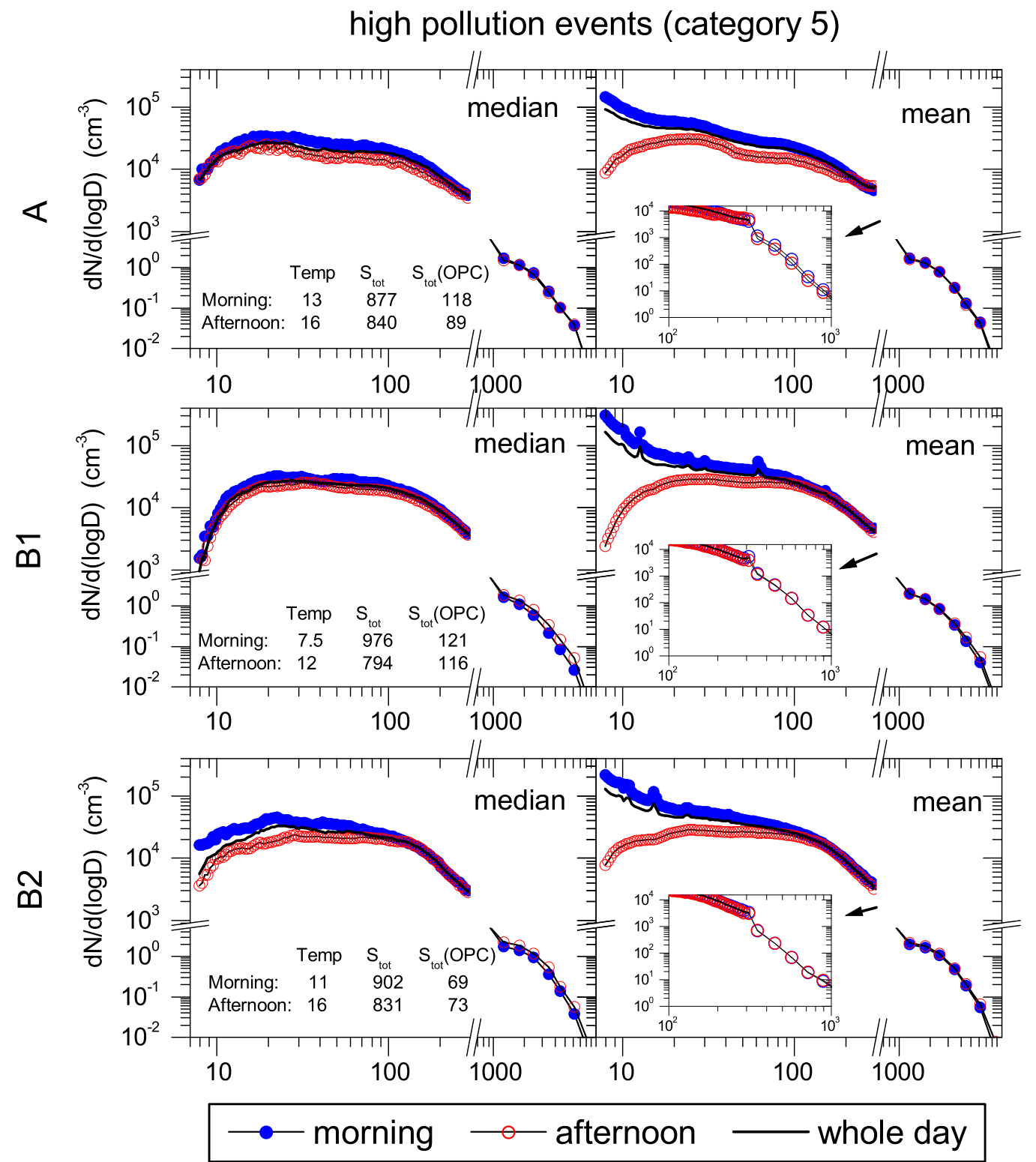

Fig. 13. SMPS $(7-310 \mathrm{~nm})$ and OPC $(0.3-10 \mu \mathrm{m})$ median and mean particle number size distributions measured during YOGAM during events with high anthropogenic pollution (event category 5, see Sect. 5). Distributions are resolved by categories A, B1 and B2, which differentiate main types of meteorological conditions during YOGAM (see text). A: high global radiation, low wind speed at high altitudes; B1: low global radiation, medium wind speed at high altitudes; B2: low global radiation, strong winds at high altitudes.

diameters is most probably due to the different refractive index and complex morphology of the measured particles in the range 300-1000 nm. In Fig. 13, presenting the highest pollution event category (downtown Zürich and morning freeway episodes), the striking difference in the morning median and mean distributions once more suggests an occurrence of heavy primary (directly traffic-related) ultrafine particle formation during strongly polluted morning events, enhanced by cold temperatures (comparable to Fig. 12). This phenomenon is strongest for category B1 (mainly cold winter days) and weakest for category A (mainly spring days), but clearly occurs in all cluster categories. In the afternoon distributions no evident differences between median and mean distributions are observed. In all cases, especially in category A, a concentration decrease in the $80-140 \mathrm{~nm}$ size range is seen. This is usually caused by increases in the mixed boundary layer height in the afternoon. Figure 14 shows the corresponding plots for data in the lowest pollution categories (1 and 2), mainly found at rural, elevated areas (see also Fig. 10). For cluster category A (mainly spring days with 


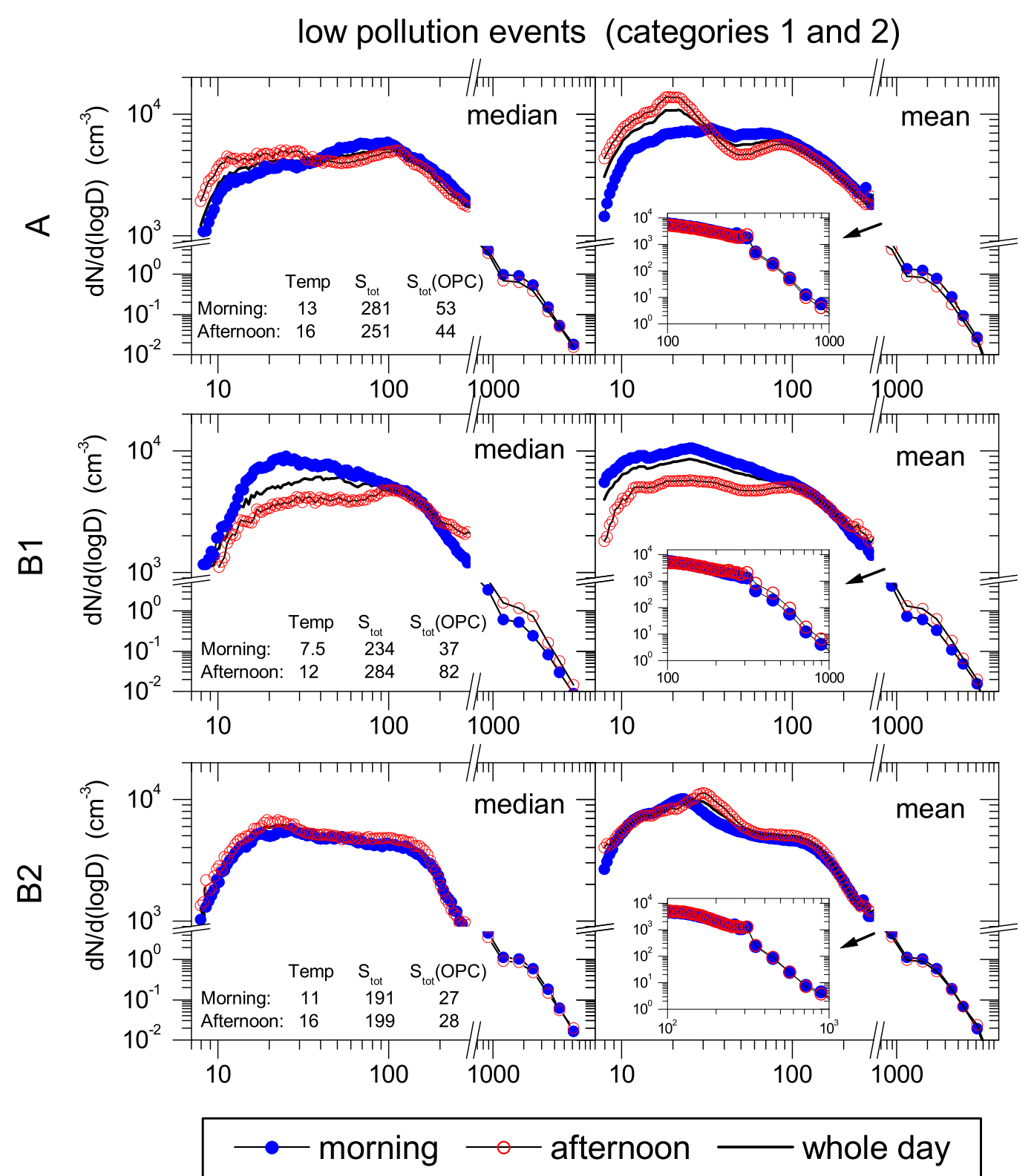

Fig. 14. SMPS $(7-310 \mathrm{~nm})$ and OPC $(0.3-10 \mu \mathrm{m})$ median and mean particle number size distributions measured during YOGAM during events with low anthropogenic pollution (event categories 1 and 2, see Sect. 5). Distributions are resolved by categories A, B1 and B2, which differentiate main types of meteorological conditions during YOGAM (see text). A: high global radiation, low wind speed at high altitudes; B1: low global radiation, medium wind speed at high altitudes; B2: low global radiation, strong winds at high altitudes.

high global radiation), a remarkable difference between median and mean distributions is seen for the afternoon distributions, which does not occur that obviously in the corresponding morning distributions and the entire rest of the cluster categories. This might be an indication that secondary ultrafine particles occurred in low polluted areas under these conditions, triggered by higher photochemical activity. Furthermore, these particles are probably not primary because they are found in the afternoon at higher temperatures than in the morning. From the size of these particles $(D \approx 20 \mathrm{~nm})$ we conclude that nucleation took place several hours before the mobile van entered the area of interest in the afternoon (typically at 2:30 pm). Similar to Fig. 13, concentrations in the $80-140 \mathrm{~nm}$ size range decrease from morning to afternoon, in this case suggesting that the rural locations were influenced by pollution also in the morning. Due to vertical mixing and dilution the concentrations decreased throughout the day. Category B2 (low global radiation and strong winds at 
high altitudes) is characterized by extraordinarily low number and surface area concentrations for particles larger than $300 \mathrm{~nm}$, yielding low values of $\mathrm{S}_{\text {tot }}$ and S(OPC). This indicates a generally clean atmosphere, associated with the high wind speeds from the west with a low residence time over the continent, and possibly resulting from precipitation on the previous hours/days causing below-cloud scavenging of large particles. The third category, B1 (low global radiation, cold temperatures), shows low concentration levels for large particles in the mornings (see also $\mathrm{S}_{\text {tot }}$ and $\mathrm{S}(\mathrm{OPC})$ ) but a large increase in the afternoon. At the same time there is a rather high number concentration (compared to the other situations) for both the median and mean distributions in the ultrafine size range in the mornings, which decreases in the afternoon. Daily morning concentrations of $\mathrm{N}(<30)$ and $\mathrm{CO}$ were correlated in this category, and the morning average temperature was low $\left(7.5^{\circ} \mathrm{C}\right)$. This suggests that the observed ultrafine particles were primary.

\section{Summary and conclusions}

It was the goal of this study to obtain an integral picture on the annual variation of fine and ultrafine aerosol levels in the Zürich area with the help of mobile measurements. We already showed earlier that mobile measurements are useful for short-term air pollution investigations that allow investigating and distinguishing between day and night situations but also between urban and rural areas within the same experiment involving a single mobile laboratory. Using appropriate multivariate statistics the same has been shown in this study to be possible also for day-to-day investigations. Overall, the total particle background number concentration was lowest at elevated rural sites. The annual average of the particle background covering all area types was $25000 \pm 20000 \mathrm{~cm}^{-3}$ (mean \pm standard deviation, $\mathrm{D}>3 \mathrm{~nm}$ ). In downtown Zürich, the annual background concentration level was $35000 \pm 30000 \mathrm{~cm}^{-3}$, while the corresponding value for rural areas was $15000 \pm 12000 \mathrm{~cm}^{-3}$. This agrees with the ranges that we presented in our previous YOGAM case study. It has been shown with Principal Component Analysis (PCA) that this trend was always true within one measuring day, and that $\mathrm{N}(80-140)$, V2.5, carbon monoxide and the active surface area are good indicators for the level of anthropogenic air pollution. Analysis of Variance (ANOVA) showed that the spatial (urban vs. rural) concentration variation was significantly smaller than the day-to-day and seasonal variation for $\mathrm{N}_{\text {tot }}$, particle background number concentration, active surface area and N(80-140), while it was more similar only for $\mathrm{N}(<30)$ and CO. Thus, meteorology governs the major annual variance of fine and ultrafine particulate air pollution in the selected area and exceeds the spatial pollution variation. Therefore, it is for example suggested for epidemiological studies to relate health effects not only to an exposure location type, but also to the influ- ence of weather conditions at a specific location. Based on PCA and cluster analysis it has also been shown that primary (directly traffic-influenced) ultrafine particles regularly occurred in highly polluted areas, with an increased formation potential at cold temperatures, which was typically the case during winter inversion episodes. Ultrafine number concentrations along a freeway stretch were consistently much higher (usually $>80000 \mathrm{~cm}^{-3}$ on average) and more regularly observed than in other urban area types. These observations agree well with previous literature. A suppression of nucleation has not been observed for high concentrations of combustion accumulation mode aerosol. There was a weak evidence for secondary (anthropogenic or biogenic) ultrafines in clean rural areas in the afternoons of warm and sunny days, mainly in spring. Their occurrence was however generally low, and number concentrations were considerably lower than for primary ultrafines. Nucleation events characterized by a "banana" shape of size distribution contour plots, as for example described by (Boy and Kulmala, 2002b), were not captured by this experiment, due to the mobile approach in this complex terrain.

These findings lead us to the conclusion that, although the selection of days was not representative for entire seasons in this study, the performed mobile measurements were suitable for pollutant assessments to obtain good information on spatial and day-to-day variability. For aspects concerning spatial resolution on a relatively short time scale ( $<1$ day), an experimental design using a mobile measurement may even be more appropriate than a network of stationary measuring sites.

Acknowledgement. We thank the canton of Zürich, the BUWAL (Swiss Agency for the Environment, Forests and Landscape) and the Zürich city authorities for their support and funding. We also would like to acknowledge E. Pretsch (ETH Zürich) for his valuable statistical advice. Last but not least we thank R. Richter for his great help during the planning and experimental phase of the project and M. Tinguely for providing meteorological and geographical data.

\section{References}

Abdul-Khalek, I. S., Kittelson, D. B., and Brear, F.: The influence of dilution conditions on diesel exhaust particle size distribution measurements, SAE Technical Paper Series, 1999-01-1142, 1999.

Abdul-Khalek, I. S., Kittelson, D. B., and Brear, F.: Nanoparticle growth during dilution and cooling of diesel exhaust: Experimental investigation and theoretical assessment, SAE Technical Paper Series, 2000-01-0514, 2000.

Baltensperger, U., Streit, N., Weingartner, E., Nyeki, S., Prévôt, A. S. H., Van Dingenen, R., Virkkula, A., Putaud, J. P., Even, A., ten Brink, H., Blatter, A., Neftel, A., and Gäggeler, H. W.: Urban and rural aerosol characterization of summer smog events during the PIPAPO field campaign in Milan, Italy, J. Geophys. Res.-Atmos., 107, 10.1029/2001JD001292, 2002. 
Birmili, W. and Wiedensohler, A.: New particle formation in the continental boundary layer: Meteorological and gas phase parameter influence, Geophys. Res. Lett., 27, 3325-3328, 2000.

Boy, M. and Kulmala, M.: The part of the solar spectrum with the highest influence on the formation of SOA in the continental boundary layer, Atmos. Chem. Phys., 2, 375-386, 2002a.

Boy, M. and Kulmala, M.: Nucleation events in the continental boundary layer: Influence of physical and meteorological parameters, Atmos. Chem. Phys., 2, 1-16, $2002 \mathrm{~b}$.

Bukowiecki, N., Dommen, J., Prévôt, A. S. H., Richter, R., Weingartner, E., and Baltensperger, U.: A mobile pollutant measurement laboratory - measuring gas phase and aerosol ambient concentrations with high spatial and temporal resolution, Atmos. Environ., 36, 5569-5579, 2002.

Capaldo, K. and Pandis, S.: Lifetime of ultrafine diesel aerosol Report for the University of Minnesota and the Coordinating Research Council under the E-43 project Diesel Aerosol Sampling Methodology, Carnegie Mellon University, Pittsburgh PA, 2001.

Chambers, J. M. and Hastie, T. J.: Statistical Models in S, Chapman and Hall, London, 1992.

Dockery, D. W., Pope, C. A., Xu, X. P., Spengler, J. D., Ware, J. H., Fay, M. E., Ferris, B. G., and Speizer, F. E.: An association between air pollution and mortality in six United-States cities, N. Engl. J. Med., 329, 1753-1759, 1993.

Donaldson, K., Li, X. Y., and MacNee, W.: Ultrafine (nanometre) particle mediated lung injury, J. Aerosol. Sci., 29, 553-560, 1998.

Hand, J. L. and Kreidenweis, S. M.: A new method for retrieving particle refractive index and effective density from aerosol size distribution data, Aerosol Sci. Technol., 36, 1012-1026, 2002.

Jolliffe, I. T.: Principal Component Analysis, Springer-Verlag, New York, 1986.

Katsouyanni, K., Touloumi, G., Spix, C., Schwartz, J., Balducci, F., Medina, S., Rossi, G., Wojtyniak, B., Sunyer, J., Bacharova, L., Schouten, J. P., Ponka, A. and Anderson, H. R.: Short term effects of ambient sulphur dioxide and particulate matter on mortality in 12 European cities: Results from time series data from the APHEA project, Br. Med. J., 314, 1658-1663, 1997.

Kaufman, L. and Rousseeuw, P. J.: Finding Groups in Data: An Introduction to Cluster Analysis, John Wiley \& Sons, New York, 1990.

Kittelson, D. B., Watts, W., and Johnson, J.: Diesel Aerosol Sampling Methodology - CRC E-43 Final Report, University of Minnesota, Minneapolis, 2002.

Kittelson, D. B., Watts, W. F., and Johnson, J. P.: Fine particle (nanoparticle) emissions on Minnesota highways, Minnesota Department of Transportation, 2001-12, 2001.
Laden, F., Schwartz, J., Speizer, F. E., and Dockery, D. W.: Air pollution and mortality: A continued follow-up in the Harvard six cities study, Epidemiology, 12, 437, 2001.

Mäkelä, J. M., Koponen, I. K., Aalto, P., and Kulmala, M.: Oneyear data of submicron size modes of tropospheric background aerosol in Southern Finland, J. Aerosol. Sci., 31, 595-611, 2000.

Mardia, K. V., Kent, J. T., and Bibby, J. M.: Multivariate Analysis, Academic Press, London, 1979.

McMurry, P. H. and Woo, K. S.: Size distributions of 3-100-nm urban Atlanta aerosols: Measurement and observations, J. Aerosol Med., 15, 169-178, 2002.

Oberdörster, G. and Utell, M. J.: Ultrafine particles in the urban air: To the respiratory tract - And beyond?, Environ. Health Perspect., 110, A440-A441, 2002.

O’Dowd, C. D., Aalto, P., Hämeri, K., Kulmala, M., and Hoffmann, T.: Aerosol formation - Atmospheric particles from organic vapours, Nature, 416, 497-498, 2002.

Paatero, P. and Hopke, P. K.: Discarding or downweighting highnoise variables in factor analytic models, Analytica Chimica Acta, 490, 277-289, 2003.

Pope, C. A., Thun, M. J., Namboodiri, M. M., Dockery, D. W., Evans, J. S., Speizer, F. E., and Heath, C. W.: Particulate air pollution as a predictor of mortality in a prospective study of United-States adults, Am. J. Respir. Crit. Care Med., 151, 669674, 1995.

Schindler, C., Künzli, N., Bongard, J. P., Leuenberger, P., Karrer, W., Rapp, R., Monn, C., and Ackermann-Liebrich, U.: Shortterm variation in air pollution and in lung function among neversmokers - The Swiss study on air pollution and lung diseases in adults (SAPALDIA), Am. J. Respir. Crit. Care Med., 163, 356361, 2001.

Tobias, H. J., Beving, D. E., Ziemann, P. J., Sakurai, H., Zuk, M., McMurry, P. H., Zarling, D., Waytulonis, R., and Kittelson, D. B.: Chemical analysis of diesel engine nanoparticles using a nano-DMA/thermal desorption particle beam mass spectrometer, Environ. Sci. Technol., 35, 2233-2243, 2001.

U.S. Health Effects Institute: Understanding the health effects of components of the particulate matter mix: Progress and next steps, HEI Perspectives, 2002.

Voss, W.: Taschenbuch der Statistik, Fachbuchverlag Leipzig im Carl Hanser Verlag, Leipzig, 2000.

Wichmann, H. E. and Peters, A.: Epidemiological evidence of the effects of ultrafine particle exposure, Philos. Trans. R. Soc. Lond. Ser. A-Math. Phys. Eng. Sci., 358, 2751-2768, 2000.

Zhu, Y. F., Hinds, W. C., Kim, S., Shen, S., and Sioutas, C.: Study of ultrafine particles near a major highway with heavy-duty diesel traffic, Atmos. Environ., 36, 4323-4335, 2002. 